\title{
Digital battery passports to enable circular and sustainable value chains: Conceptualization and use cases
}

\author{
Katharina Berger *, Josef-Peter Schöggl, Rupert J. Baumgartner \\ Christian Doppler Laboratory for Sustainable Product Management Enabling a Circular Economy, Institute of Systems Sciences, Innovation and Sustainability Research, \\ University of Graz, Merangasse 18/I, 8010, Graz, Austria
}

\section{A R T I C L E I N F O}

Handling Editor: Mingzhou Jin

\section{Keywords:}

Electric vehicle battery

Sustainable product management

Decision-making

Digital product passport

\begin{abstract}
A B S T R A C T
With respect to sustainable product management, the transition to circular battery value chains requires that stakeholders have access to high-quality data for decision-making purposes. In such a context, digital battery passports (DBPs) can act as a valuable data source and thus enable greater sustainability and circularity. The present paper presents a DBP concept for an electric vehicle battery (EVB), and delineates, for the first time, the respective information requirements needed. Development of the DBP concept outlined here entailed stakeholder mapping, a systematic literature review, and a bottom-up approach. The concept comprises 54 data points, subsumed under four main information categories: (1) battery, (2) sustainability and circularity, (3) diagnostics, maintenance, and performance, and (4) value chain actors. The concept further details the information needed to enable sustainable and circular value chains. In addition, four potential DBP use cases of distinct EVB value chain stakeholders are presented in order to illustrate how the concept may be used to support sustainable product management. The contribution of the paper is threefold: firstly, it stimulates scientific debate concerning the potential of DBPs for sustainable product management. Secondly, the concepts described in this paper can be viewed as a guide for the development of other digital product passports and may thus serve to improve sustainable circular product management in general. Thirdly, it aids policymakers and practitioners when implementing DBPs.
\end{abstract}

\section{Introduction}

Digital product passports (DPPs) are often described as unique product identifiers, and serve as a useful source of life cycle data (European Commission, 2020a) for value chain stakeholders wishing to support sustainable product management (SPM). Thus, DPPs are increasingly being considered as potential enablers in the transition to more sustainable and circular production and consumption systems (Adisorn et al., 2021; European Commission, 2020a; Walden et al., 2021). While the idea behind DPPs is not novel (Adisorn et al., 2021; Honic et al., 2019a; Luscuere, 2017; Portillo-Barco and Charnley, 2015), they have recently gained the attention of policymakers, and the European Commission (EC) is now demanding their implementation
(European Commission, 2020b). In particular, the EC's proposal for new regulation of batteries and waste batteries explicitly requires the implementation of digital battery passports (DBP) for industrial batteries and electric vehicle batteries (EVBs) by January 2026 (European Commission, 2020a). However, there is still a lack of a clearly defined DBP scope in terms of information content and use cases. Thus, the discussion and pursuit of DBP implementation has sharply increased as of late, in particular amongst practitioners and non-governmental institutions (e.g., CEWI, 2021; Circular Economy Initiative Deutschland, 2020; Circulor, 2021; Global Battery Alliance, 2020; Roman, 2021; World Economic Forum, 2019). With respect to scientific coverage, however, as of now there is only a scarce number of DPP-related studies available (Adisorn et al., 2021; Gligoric et al., 2019; Honic et al., 2019c;

Abbreviations: B2U, battery second life; BMS, battery management system; BoL, beginning-of-life; DBP, digital battery passport; DMP, digital material passport;

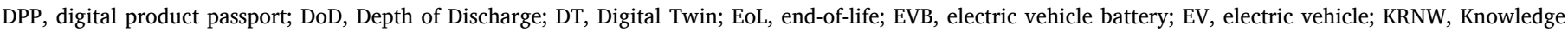

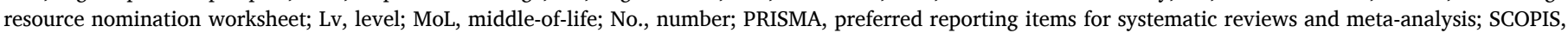

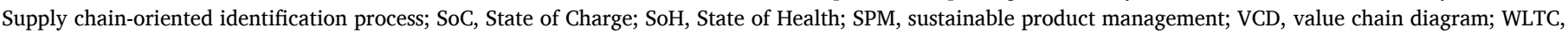
Worldwide harmonized Light vehicles Test Procedure.

* Corresponding author.

E-mail address: katharina.berger@uni-graz.at (K. Berger). 
Portillo-Barco and Charnley, 2015; Walden et al., 2021). As a result, there is currently a lack of scientific debate when it comes to DPPs and DBPs in the context of SPM. However, such scientific debate is clearly needed given the expected increase in EVB production volumes and the impact of EVBs on sustainability (Albertsen et al., 2021; Mayyas et al., 2019; Wrålsen et al., 2021). Without such debate, DBP-related development (including information content) is likely to be driven by the interests of policymakers and practitioners, possibly resulting in a weakening of the shift towards greater circularity and sustainability in the value chain.

In light of the increasing importance to manage EVBs sustainably, and the relative dearth of research on DBPs, the present paper sets out to initiate scientific debate on DBPs by providing a first systematic delineation of the informational needs of potential DBP users in the EVB value chain. The focus here is placed on sustainability and circularity-related requirements. Thus, the main research question pursued in this paper reads as follows:

RQ: What kind of information does a DBP for an EVB need to provide in order to help DBP users in their efforts to enhance the sustainability and circularity performance of EVBs and their respective value chains?

In order to identify the relevant information requirements, potential DBP users first had to be identified. Subsequently, their respective decision-making situations, as related to sustainable EVB management in the context of a circular economy, then needed to be understood in order to derive the requisite information for decision-making support purposes. Thus, the following sub-questions also needed to be addressed:

SRQ 1: Who are the potential users of an EVB digital battery passport?

SRQ 2: Which potential use cases may be supported by a DBP?

The present paper culminates in providing a DBP concept in the context of SPM. Throughout the paper the term SPM is used as an umbrella term to designate all those actions needed to enhance a product's sustainability performance (i.e., environmental sustainability, and social sustainability), as viewed from the perspective of various value chain actors, over (potentially) multiple life cycles. Such actions include (but are not limited to) sustainable supply chain management, product design and assessment, and end-of-life handling. Thus, as used here, the term SPM also includes circularity-related strategies such as recycling or reuse. This is in line with the understanding that the circular economy is only one among several complementary strategies for achieving sustainable development (e.g., Geissdoerfer et al., 2017; Saroha et al., 2021; Schöggl et al., 2020).

The remainder of this paper is structured as follows: Firstly, an overview of the theoretical background of (i) sustainable and circular value chains, and digitalization, and (ii) DBPs in the context of SPM is given, followed by the applied methods. Results are then presented, namely the developed DBP concept, as well as four use cases covering distinct EVB value chain stakeholders in order to illustrate how the DBP may be used to support SPM activities. This is followed by the discussion of the developed concept. Lastly, conclusions and implications, together with final comments on possible future research are provided.

\section{Theoretical background}

\subsection{Sustainable and circular value chains, and digitalization}

Circular value chains are in general perceived to yield various sustainability-related benefits (e.g., the securing of raw material supplies, an increase in social equity, relief of environmental stresses, economic benefits, etc.) when compared to traditional linear value chains (Birkel and Müller, 2021; Buruzs and Torma, 2017; Harris et al., 2020; Millar et al., 2019; Oliveira et al., 2021). As a result, it is often assumed that such value chains may be used to facilitate SPM efforts (Batista et al., 2018; Kayikci et al., 2021; Kumar et al., 2021; Schöggl et al., 2020; Wrålsen et al., 2021). Hence, policymakers are pushing for the transition towards more circular value chains by introducing respective regulatory mandates (European Commission, 2020a). This, in turn, increases pressure on respective stakeholders to pursue appropriate strategies.

In pursuing greater circularity, however, value chain stakeholders face several difficult decisions. On the one hand, they need to determine and decide upon appropriate value chain loop-closing pathways, the employment of secondary material, or the selection of suppliers (Alamerew and Brissaud, 2020; Albertsen et al., 2021; de Oliveira et al., 2021; Julianelli et al., 2020). On the other hand, as increased circularity does not necessarily equate with lower environmental or social impacts, they might also want to optimize the sustainability performance of their product systems (de Oliveira et al., 2021; Harris et al., 2020; Kirchherr et al., 2017; Oliveira et al., 2021; Schöggl et al., 2020). To ease SPM-related decision-making, value chain stakeholders thus require high-quality data and practical tools (de Oliveira et al., 2021; Ellingsen et al., 2017; Harris et al., 2020; Kayikci et al., 2021; Saidani et al., 2019). However, such high-quality data is largely lacking due to frequent data losses along value chains (e.g., resulting from poor documentation, lack of willingness to share data, etc.) (Honic et al., 2019c; Kayikci et al., 2021; Kouhizadeh et al., 2021). Digital technologies can be a great aid in light of these challenges.

In the relevant literature reference is often made to 'industry 4.0' (e. g., Bag et al., 2021; Birkel and Müller, 2021; Esmaeilian et al., 2020) and 'blockchain technology' (e.g., Esmaeilian et al., 2020; Saberi et al., 2019; Zhang et al., 2020), in order to emphasize the contribution that digital technologies may make to the improvement of value chain sustainability. A further digital technology offering considerable promise in SPM is that of the 'digital twin' (Jones et al., 2020). A digital twin (DT) is initially described as a virtual real-time representation of a physical product that is able to gather, contain and monitor, in real-time, the value chain and life cycle data of its physical counterpart (Jones et al., 2020). As such, a DT is perceived as being a potential enabler of DPPs (Circular Economy Initiative Deutschland, 2020; Heinrich and Lang, 2019), which in turn are perceived as being substantial enablers in the shift towards a sustainable circular economy (European Commission, 2020a; Walden et al., 2021; World Economic Forum, 2019).

\subsection{Digital battery passports in the context of SPM}

A DPP incorporates value chain and life cycle data which is unique to a specific product (European Commission, 2020a). Thus, DPPs can serve as a valuable data source for value chain stakeholders in the context of SPM (Honic et al., 2019). Owing to their numerous benefits, DPPs have recently gained increasing attention among policymakers (European Commission, 2020a, 2020b, 2020a). Such benefits are, for example, the provision of general product information or the provision of information on product sustainability and circularity performance (Heinrich and Lang, 2019). Hence, DPPs are perceived as being clear enablers with respect to sustainable product life cycle management and the promotion of value-retaining operations, and thus as instruments capable of facilitating more sustainable and circular value chains (Heinrich and Lang, 2019; Honic et al., 2019a). Recently, owing to the EC's proposal for new regulation on batteries and waste batteries, DPPs have gained importance in the context of circular battery value chains. Such regulation demands the implementation of maximum life cycle carbon footprint thresholds and of minimum shares for recovered active material content for batteries, as well as the implementation of DBPs (European Commission, 2020a). In particular the implementation of DBPs for EVBs is of interest. Given the ongoing efforts to electrify and decarbonize transport systems, the production volumes of EVBs are expected to rise dramatically in coming years (Rafele et al., 2020; Stampatori et al., 2020). Besides environmental, geopolitical and social issues are also expected to further the adoption of DBPs. For example, EVBs often contain critical 
raw materials (e.g., lithium, natural graphite and cobalt) (Mayyas et al., 2019; Rafele et al., 2020; Stampatori et al., 2020), or may be associated with poor working conditions or human rights problems in the upstream supply chain (Albertsen et al., 2021; Mayyas et al., 2019; Sovacool et al., 2019). In such a context, a DBP could adopt a role as enabler in the creation of sustainable and circular EVB value chains. However, this requires that DBPs provide users with meaningful SPM information and decision-making support (de Oliveira et al., 2021; Honic et al., 2019c). To date, however, DBP development is mainly being pursued by practitioners, non-governmental institutions, and policymakers (e.g., CEWI, 2021; Circulor, 2021; European Commission, 2020a; Global Battery Alliance, 2020; Roman, 2021; World Economic Forum, 2019). In addition, clear specifications regarding DBP scope and use cases are currently lacking (European Commission, 2020a, 2020b, 2020a), resulting in different industry driven visions regarding DPPs and DBPs (e.g., CEWI, 2021; Global Battery Alliance, 2020; Roman, 2021).

Very few studies exist which provide an overview of DPP potentials in the context of a circular economy (Adisorn et al., 2021; Walden et al., 2021), or which investigate potential technologies (e.g., smart tags, sensors) to capture and carry DPP data (Gligoric et al., 2019; Portillo-Barco and Charnley, 2015). A slightly higher number of studies exist which focus on digital material passports (DMPs) in the context of the circular built environment (Honic et al., 2019a, 2019b, 2021, 2019b). With respect to DBP-related research Bai et al. (2020) briefly mention DBPs and their potential in supporting battery recycling efforts (e.g., quick identification of material composition to enhance sorting efficiency). Other than that, DBP-related studies in an SPM context are at present, more or less non-existent. ${ }^{1}$ There thus appears to be a risk of neglecting the potential of DBPs in contributing to SPM. Thus, scientific debate of DBPs is needed to facilitate exchange with the industry and policymakers, allowing to exchange perspectives and maximize the potential of DBPs contributing to SPM.

\section{Methods}

The DBP concept presented in this paper was developed in the following three research stages: (1) stakeholder mapping in accordance with the supply chain-oriented identification process (SCOPIS) (Fritz et al., 2018), (2) a systematic literature review corresponding to the preferred reporting items for systematic reviews and meta-analysis (PRISMA) guidelines (Moher et al., 2009) for use case development purposes, and (3) bottom-up concept development (see Fig. 1).

\subsection{Research stage one: stakeholder mapping}

Research stage one comprised engaging in stakeholder mapping in accordance with the SCOPIS (Fritz et al., 2018). This approach served to identify the direct and indirect stakeholders of the EVB value chain, and thus to identify potential DBP users. SCOPIS comprises several phases (see Fig. 1), such as a systematic literature review, value chain diagram (VCD) development, validation, and adaptation (Fritz et al., 2018). A SCOPIS-related systematic literature review was used to develop the first VCD iteration, and was conducted according to the PRISMA guidelines (Moher et al., 2009). The first VCD iteration was subjected to a validation process conducted by the authors' research group, which consisted of seven members with an academic background in sustainable product and supply chain management, sustainability assessment, and the circular economy. The output generated from this validation process was incorporated into the VCD, enabling development of the second iteration. The second iteration was then subjected to a preliminary expert validation process conducted by three industry experts. Expert recruitment followed the knowledge resource nomination worksheet (KRNW)

\footnotetext{
${ }^{1}$ A Scopus search (as of February 2022) yielded zero results for the keyword "digital battery passport".
}

approach (Okoli and Pawlowski, 2004), that was applied to the author's network of industry partners.

With respect to the expert selection criteria employed, only those experts were considered who were affiliated with EVB-related industries and had at least four years of experience in respective industries. For more detailed information on the profiles of the experts consulted see Table 1 . The VCD validation provided by industry experts then allowed for the development of the VCD version (see appendix A, Fig. A1) used to proceed with research stage two.

\subsection{Research stage two: systematic literature review and use case development}

Research stage two comprised a stand-alone systematic literature review conducted according to PRISMA guidelines (Moher et al., 2009). This provided the background for developing the potential SPM-related decision-making situations, and thus the DBP use cases, in the context of sustainable battery management.

\subsubsection{Systematic literature review: identification}

The systematic literature review was conducted between November 2020 and January 2021, and an initial sample of 1140 peer-reviewed references and 50 grey literature references was identified (see Fig. 2).

To identify suitable peer-reviewed references (e.g., research articles, review papers, conceptual papers) the database Scopus was used. With respect to identifying relevant grey literature (e.g., pre-prints, PhD's theses, reports, conference contributions, product specification sheets), a KRNW approach (Okoli and Pawlowski, 2004) was first followed in order to identify potential grey literature sources. Thus, grey literature was treated as a source of expert knowledge in order to counteract any potential publishing bias towards academia (Haddaway and Bayliss, 2015) that manifests itself in the dearth of DBP research. On the other hand, there is an over proportional number of DBP grey literature stemming from the industrial environment, resulting in the industrial environment being more advanced than research.

The first KRNW iteration was developed by drawing on Okoli and Pawlowski (2004) concerning potential organization types (e.g., academia, practitioners, governmental bodies) providing relevant grey literature. The search engines Google Scholar and Ecosia were used to identify such organization types by name, as well as the related grey literature. The final iteration of the KRNW contains grey literature sources, such as institutions from academia (e.g., universities), practitioners and consortia (e.g., European Battery Alliance, Global Battery Alliance, CATL, BASF, Umicore), governmental bodies (e.g., European Commission, Australian Trade and Investment Commission), and non-profit organizations (e.g., Ellen McArthur foundation) (see appendix A, table A2).

A list of exemplary keywords for (peer-reviewed and grey) literature search purposes can be found in appendix A (see table A1).

To derive the initial sample of references the following selection criteria were employed. Firstly, publications in the English and German language, published between 2010 and 2021, were considered. This specific time horizon was chosen owing to the fact that electric vehicles (EV) entered the mass market in 2009 (Tsakalidis and Thiel, 2018). Targeting publications written in English was considered justified because it allowed us to access a broad pool of references, and English is a primary working language in the international scientific community (Ferguson, 2011). As Germany is one of the leading automotive producing economies in the world (Bundesministerium für Wirtschaft und Energie, 2020), targeting publications written in German enabled us to gain additional access to automotive-related references. Owing to the global character of EVB value chains (Rafele et al., 2020), publications were not excluded based on their geographical context.

\subsubsection{Systematic literature review: screening}

After removing duplicates from the initial sample of references, 972 


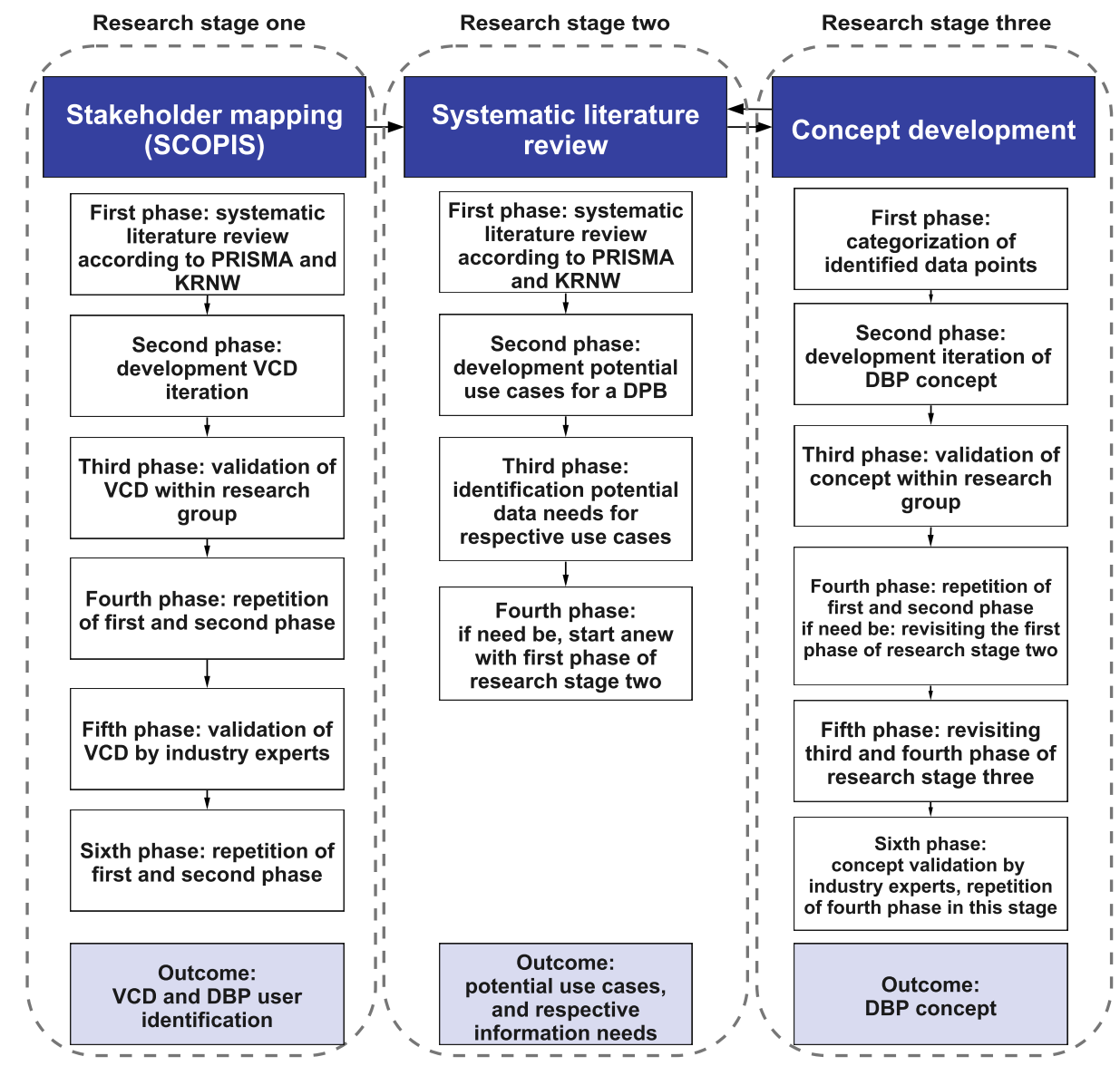

Fig. 1. The research design followed in the development of the DBP concept (own depiction). DBP = digital battery passport. SCOPIS $=$ supply chain-oriented identification process. $\mathrm{VCD}=$ value chain diagram. KRNW $=$ Knowledge resource nomination worksheet.

Table 1

Profile of consulted experts.

\begin{tabular}{|c|c|c|c|c|c|}
\hline $\begin{array}{l}\text { Expert } \\
\text { Number }\end{array}$ & $\begin{array}{l}\text { Current professional } \\
\text { affiliation }\end{array}$ & $\begin{array}{l}\text { Current role within } \\
\text { organization }\end{array}$ & Expertise & Country & $\begin{array}{l}\text { Years of } \\
\text { experience }\end{array}$ \\
\hline Expert 1 & $\begin{array}{l}\text { Automotive engineering } \\
\text { center }\end{array}$ & Coordinator global research & $\begin{array}{l}\text { Powertrain engineering; } \\
\text { Driving innovation; } \\
\text { Evaluation of novel business cases within the automotive } \\
\text { industry }\end{array}$ & Austria & 32 \\
\hline Expert 2 & $\begin{array}{l}\text { Automotive engineering } \\
\text { center }\end{array}$ & Project manager & $\begin{array}{l}\text { Electric vehicle development, prototyping and production; } \\
\text { Battery concept development, prototyping and production; } \\
\text { Product engineering }\end{array}$ & Austria & 11 \\
\hline Expert 3 & $\begin{array}{l}\text { Automotive engineering } \\
\text { center }\end{array}$ & $\begin{array}{l}\text { Technical legislation } \\
\text { specialist }\end{array}$ & $\begin{array}{l}\text { Legislation related to vehicle emissions, fuel and energy } \\
\text { consumption; } \\
\text { Legislation related to vehicles in general; } \\
\text { Legislation related to sustainability requirements of vehicles }\end{array}$ & Austria & 4 \\
\hline
\end{tabular}

references remained. These references were then screened with respect to title and abstract. Publications were excluded when they were found to have no relation to the EVB value chain or life cycle, to digital product or battery passports, or to potential SPM-related decision-making situations and respective data needs in an EVB context. After the title and abstract screening stage, 436 references remained (see Fig. 2).

\subsubsection{Systematic literature review: eligibility and inclusion}

These remaining references were then subjected to a full-text screening process. During this stage additional references were identified by following the snowballing principle. With respect to selection criteria, the same criteria were employed as in the title and abstract screening stage. After the full-text screening, 240 references remained. These references were then subjected to a full-text analysis. The full-text analysis led to a final sample of 129 references comprising peerreviewed articles and grey literature (see Fig. 2).

\subsubsection{Use case development}

The preceding stages served to help develop potential DBP use cases by analyzing their respective results. This allowed us to identify potential SPM-related decision-making situations for EVB value chain stakeholders (e.g., product design and development, purchasing decisions, end-of-first-life treatments) (Adisorn et al., 2021; de Oliveira et al., 2021; Honic et al., 2019a, 2019c; Julianelli et al., 2020). Based on those decision-making situations, relevant information needs and requirements were then derived, and these served as a prerequisite in the development of the DBP concept presented here. 


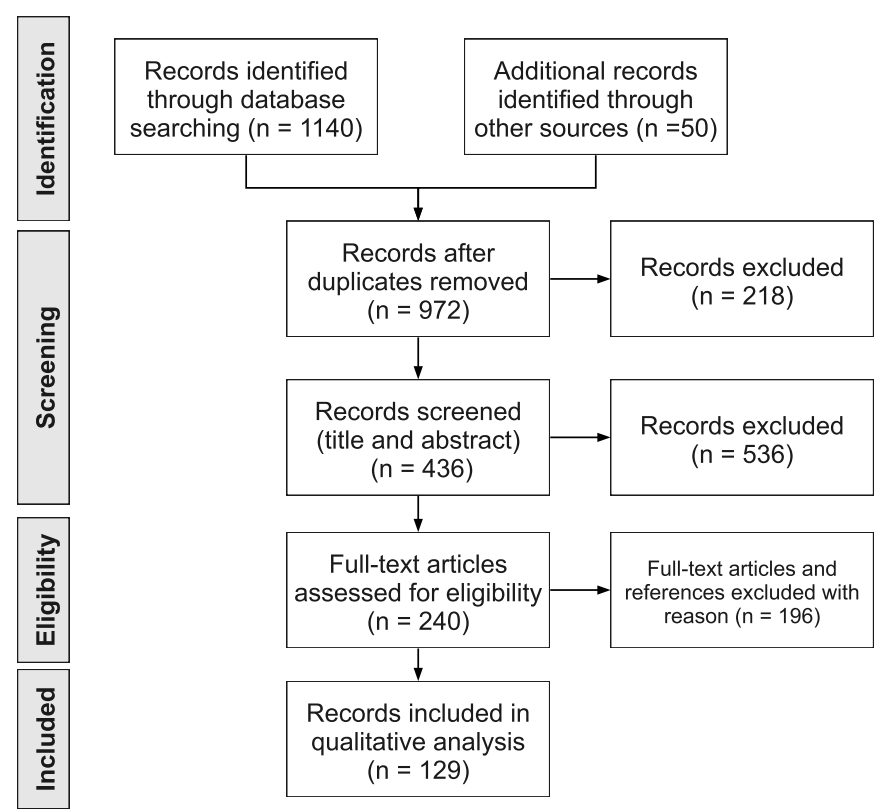

Fig. 2. Literature review process of research stage two according to PRISMA (Moher et al., 2009). PRISMA = preferred reporting items for systematic reviews and meta-analysis.

\subsection{Research stage three: concept development}

Based on the results obtained in the preceding stages, research stage three was then dedicated to developing the DBP concept presented in the present paper. The information (e.g., on battery type, battery state-ofhealth, $\mathrm{CO}_{2}$ footprint) derived from preceding research stages was categorized and structured in a bottom-up approach in order to develop the first iteration of the concept. The first DBP concept iteration was subjected to a validation process conducted by the authors' research group. The output obtained from the initial validation process was incorporated into the first concept iteration. Subsequently, an additional literature review was conducted in order to further build on the initial validation output. The concept validation process conducted by the authors' research group was repeated three additional times, resulting in six DBP concept iterations. The sixth iteration was subjected to a preliminary validation procedure carried out by the same industry experts as in research stage one (see Table 1), and the same expert selection criteria were applied.

\section{Conceptualization of a digital battery passport}

This section provides an outline of the resulting DBP concept (see Fig. 3). The concept comprises 54 data points (see appendix A, table A3) and four information categories. These categories provide DBP users with information for contextualization purposes, and with information for SPM decision-making in connection with an EVB and its respective value chain. The four categories devised were labelled as follows: (1) Battery, (2) sustainability and circularity, (3) diagnostics, performance, and maintenance, and (4) value chain actors. Seven information levels are employed in the DBP concept in order to provide a more meaningful informational structure. It has to be noted that at this DBP concept development stage user roles (including data access rights) have not been defined yet.

An in-depth description of each information category, with respect to content and function, as well as of the respective development process is now provided below.

\subsection{Battery}

To enable SPM efforts (e.g., conducting life cycle assessments, assessing circularity performances) the product of interest needs to be clearly identified (Honic et al., 2019a). This allows respective decision-makers to generate an understanding of the product of interest, thus leading to contextualization (Honic et al., 2019c). Thus, the main information category battery allows for product identification, and contextualization (see Fig. 4).

Subsequent category development was inspired by consulting policymaker publications (European Commission, 2020a), and circular economy-related initiatives (Circular Economy Initiative Deutschland, 2020). In addition, literature with a focus on DMPs (e.g., Heinrich and Lang, 2019; Honic et al., 2019b; Honic et al., 2019a), EVB performance (e.g., Chen et al., 2020; Philippot et al., 2019; Stampatori et al., 2020) and structure (e.g., Bai et al., 2020; Coffin and Horowitz, 2018; Jussani et al., 2017), also served as a source of inspiration. Moreover, literature with a focus on digitalization and the circular economy (e.g., Garrido-Hidalgo et al., 2020; Saberi et al., 2019; Wang and Wang, 2019) was also consulted and used as a source of inspiration for category development.

Category-related information can be further divided into two sub-

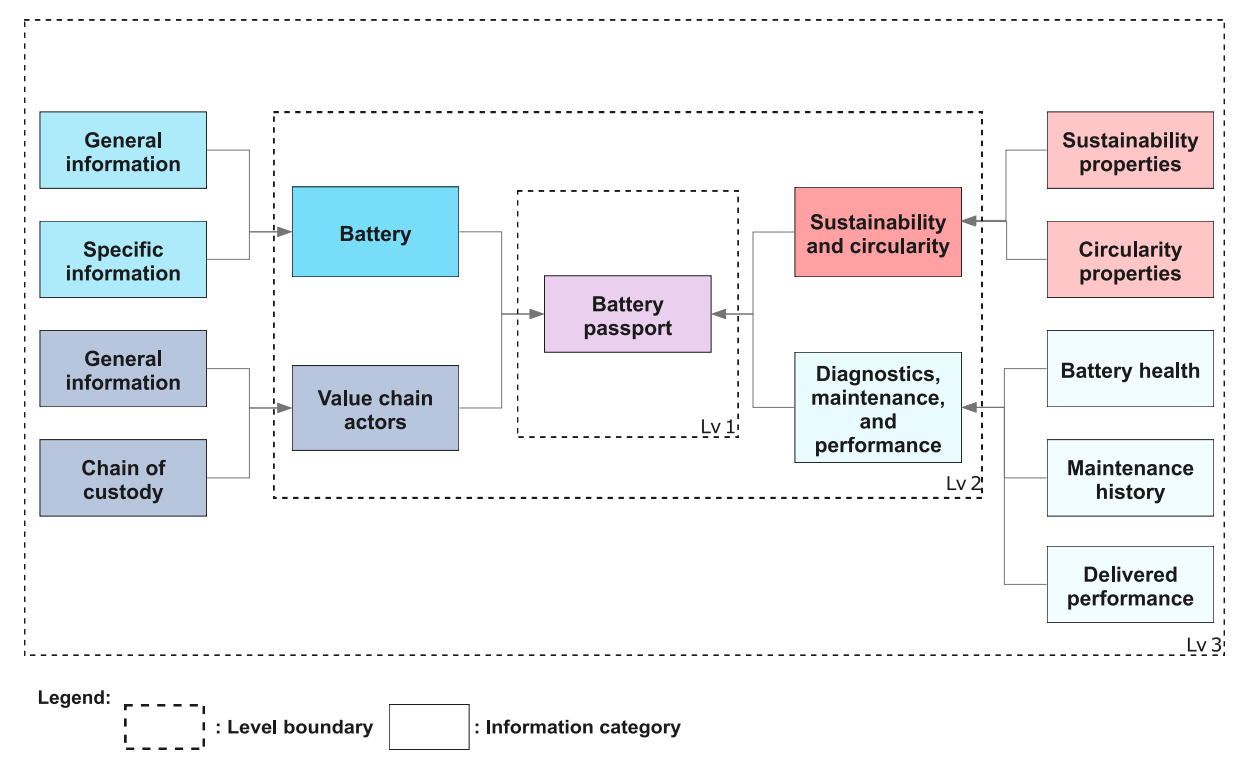

Fig. 3. Overview of digital battery passport concept, showcasing its first three information levels and related categories (own depiction). Lv $=$ level. 


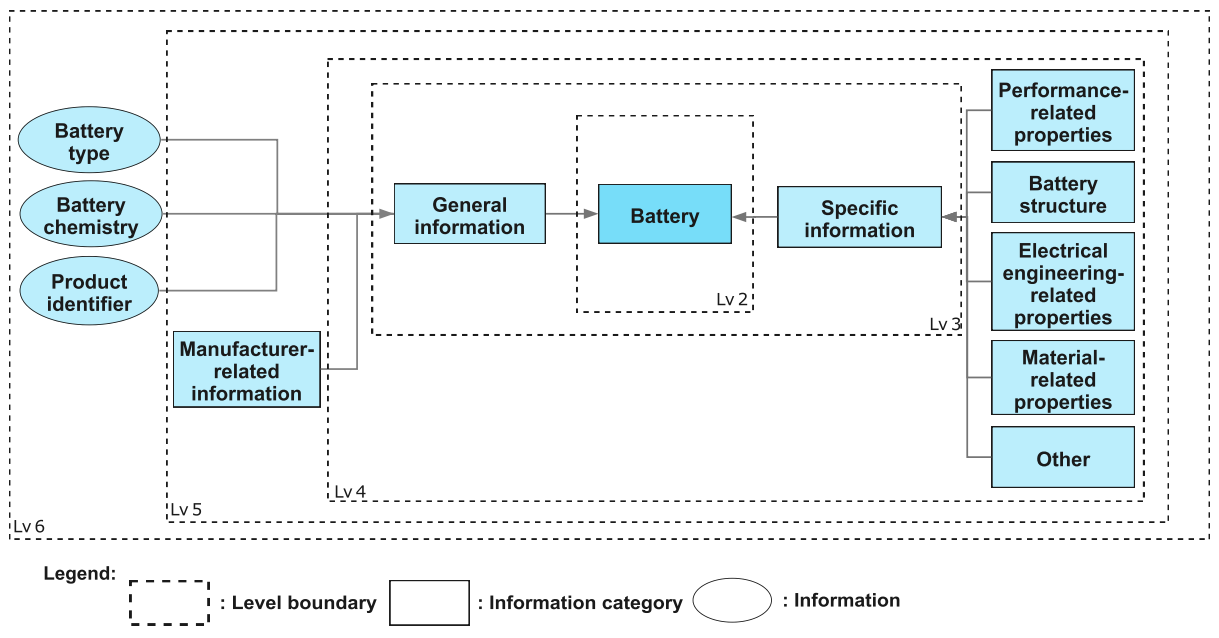

Fig. 4. Main information category battery with respective sub-categories and information level structure (own depiction). Lv $=$ level.

information categories: general product information (see Fig. 5) and specific product information (see Fig. 6). A more detailed description of these sub-categories and their information content is provided in the following two sub-sections.

\subsubsection{General product information}

The sub-category general product information includes the basic product specifications for the EVB of interest. This enables DBP users to engage in clear contextualization and EVB identification, an essential process in SPM (Honic et al., 2019c).

This sub-category thus contains information on the battery application type (e.g., EVB, energy storage battery), battery chemistry (including electrodes and electrolyte) employed, battery identifier (e.g., serial number, batch number), and related manufacturing information (e.g., battery pack manufacturer, location of production site).

\subsubsection{Specific product information}

After the initial identification of the product of interest, further contextualization might be necessary, depending on the use case at hand. End-of-life-related actors, for example, might require additional information (e.g., battery structure, employed materials) for safe EVB handling purposes. As a result, the sub-category specific information provides information that allows the user to develop a deeper understanding of the EVB of interest (see Fig. 6). This sub-category allows DBP users to obtain information on battery performance-related properties (e.g., driving range, lifespan, charging time) (e.g., Jussani et al., 2017; Olivetti et al., 2017); battery structure-related specifications with respect to cell, module, and pack level (e.g., total number of cells and modules, number of cells per module, employed assembly processes) (Harper et al., 2019; e.g., Kiemel et al., 2020); electrical engineering-related specifications (e.g., energy density, power density) (e.g., Casals et al., 2019; Jussani et al., 2017; Olivetti et al., 2017); and material-related information (e.g., bill of material, supplier responsible, location of production) (e.g., Bai et al., 2020; Harper et al., 2019; Jussani et al., 2017; Sovacool et al., 2019).

\subsection{Sustainability and circularity}

To ensure the pursuit of sustainable EVB value chain loop-closing pathways, DBP users require information on the sustainability- and circularity-performance of the EVB of interest (Harris et al., 2020; Saidani et al., 2019). Thus, after contextualization has been provided by the information category battery, the main information category sustainability and circularity provides DBP users with information on the sustainability- and circularity-related properties of the EVB of interest.

Category development was inspired by consulting policymaker publications (European Commission, 2020a); literature related to DMPs (e.g., Heinrich and Lang, 2019; Honic et al., 2019a; Honic et al., 2019b), and to digitalization and the circular economy (e.g., Kouhizadeh et al., 2021; Saberi et al., 2019; Wang and Wang, 2019). Furthermore,

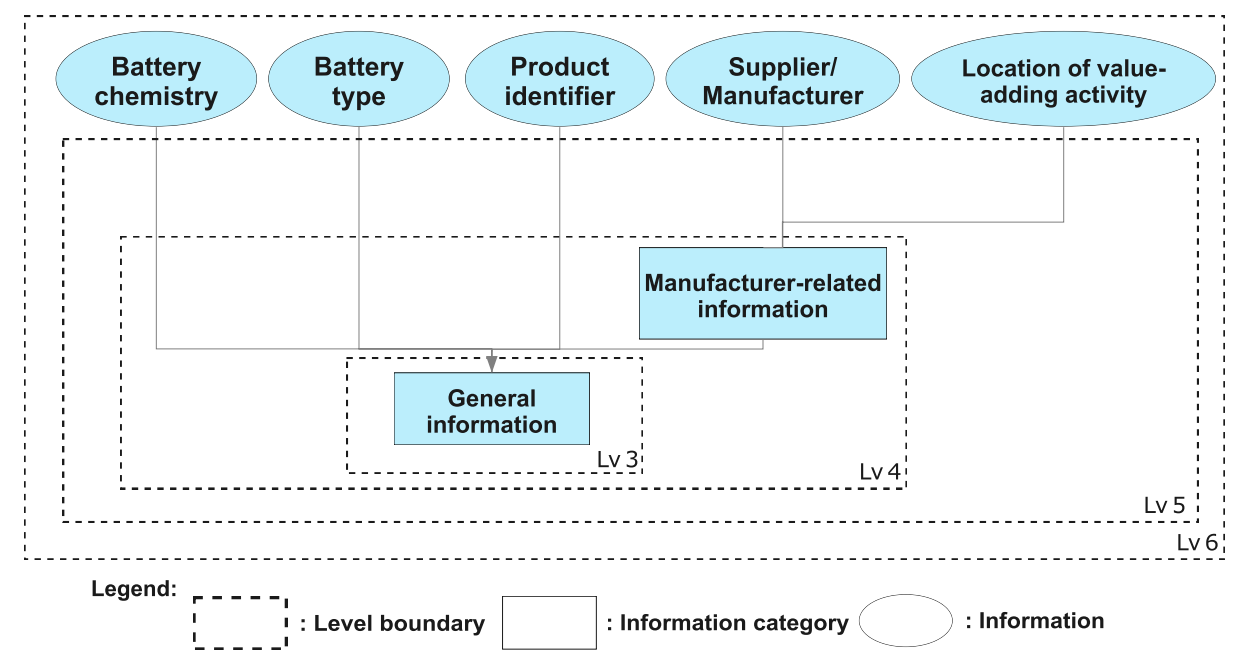

Fig. 5. Sub-information category general information with respective sub-information categories located on deeper information levels (own depiction). Lv $=$ level. 


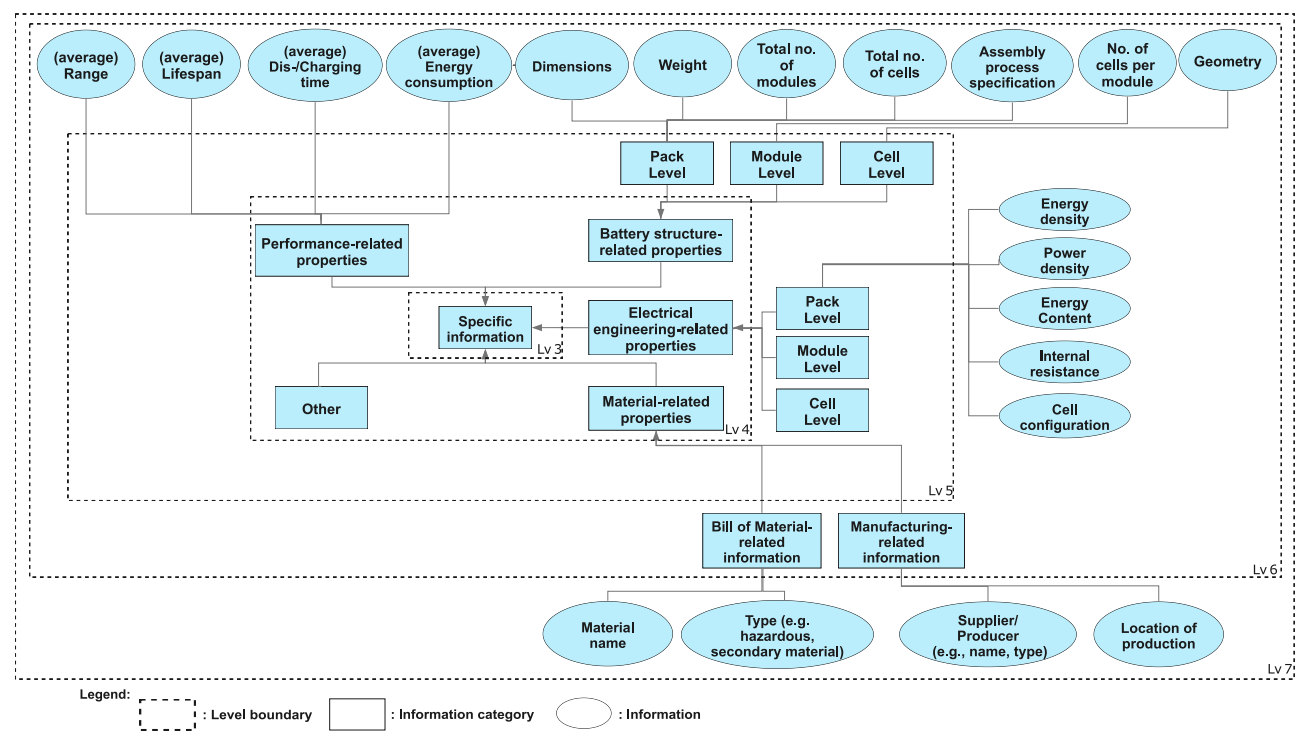

Fig. 6. Sub-information category specific product information with respective sub-information categories located on deeper information levels (own depiction). No. $=$ number. WLTC $=$ Worldwide harmonized Light vehicles Test Procedure. Lv $=$ level.

literature on EVBs, with a focus on end-of-life treatment (e.g., Bai et al., 2020; Hua et al., 2020; Reinhardt et al., 2019), also served as source of inspiration.

Category-related information can be further divided into two subinformation categories: sustainability properties and circularity properties (see Fig. 7). A more detailed description of these sub-categories, and their information content is now provided in the two sub-sections below.

\subsubsection{Sustainability-related properties}

The sub-information category sustainability-related properties allows DBP users to derive information on the environmental and social impact of an EVB. Furthermore, it provides information on respective impact categories, on performance indicators, indicator calculation methods, inventory data employed and the respective data sources, as well as on the applied standards and impact assessment methods with respect to the underlying information levels. Such information allows DBP users to further enhance their understanding of related sustainability impacts and also serves to raise overall transparency. With a view to representing environmental and social impacts, we suggest making use of the following indicator set: With respect to EVB environmental performance, and in accordance with recent regulatory proposals (European Commission, 2020a), we advise that a DBP must at least provide data on the related $\mathrm{CO}_{2}$ footprint. Furthermore, environmental impact-related indicators, such as those related to energy consumption (e.g., the cumulative energy demand), water use, land use, and toxicity, should all be included as part of a DBP so as to provide users with a more comprehensive understanding concerning the EVB's environmental performance. With respect to the social performance, we propose that a DBP provide indicators related to working conditions (e.g., indicators related to child labor, forced labor, pay levels, safety of working conditions). The suggested indicator types derive from policymaker publications (European Commission, 2020a), as well as sustainability reports of original equipment manufacturers (OEM) (e.g., BMW Group, 2019; Nissan Motor Corporation, 2019; Tesla Inc., 2020). Additionally, literature focusing on life cycle assessment (LCA) in the automotive industry (e.g., Bobba et al., 2018; Cusenza et al., 2019; Ellingsen et al., 2014) and on DMPs (e.g., Honic et al., 2019a; Honic et al., 2019c) inspired suggested indicator types.

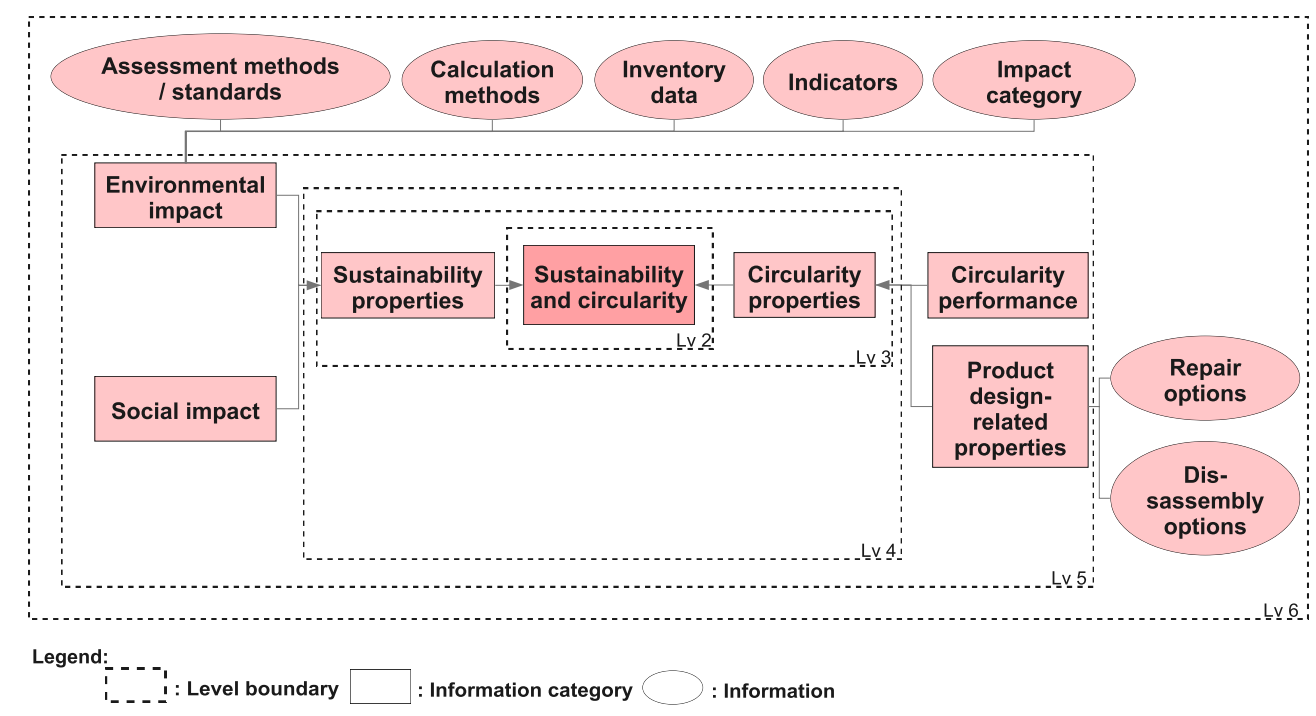

Fig. 7. Main information category Sustainability and circularity with respective sub-information categories (own depiction). Lv $=$ level. 


\subsubsection{Circularity-related properties}

The information sub-category circularity-related properties allows DBP users to derive information on an EVB's circularity performance. The category's information content and structure follows the same logic as that illustrated in the preceding sub-section. With respect to representing the circularity performance on the micro level, the same reasoning as presented in the preceding sub-section is also applied. Thus, a DBP ought to provide a set of indicators relating to resource efficiency, input reduction and/or use of natural resources, (raw) material losses, the share of secondary material within the EVB, and increase in durability and useful lifespan of the EVB. The indicator types suggested have been derived by consulting literature focusing on circularity performance assessment (e.g., Elia et al., 2017; Parchomenko et al., 2019; Saidani et al., 2019) and on DMPs (Heinrich and Lang, 2019; Honic et al., 2019b), as well as by reviewing policymaker publications (European Commission, 2020a).

\subsubsection{Product design}

The information sub-category product design allows DBP users to derive information on battery module employed and on pack assembly processes (e.g., welding, gluing, wiring), product designs (e.g., design for recycling, design for reuse), and on disassembly instructions. Such information may, for example, be of use to actors involved in product end-of-life activities seeking to improve the safety of EVB handling and disposal (Bai et al., 2020; Harper et al., 2019).

\subsection{Diagnostics, maintenance, and performance}

When an EVB ends its first useful life it may still qualify for use in a second life (Albertsen et al., 2021; Reinhardt et al., 2019). To decide whether an EVB, or rather respective modules are a second life or a recycling case, end-of-first-life-related actors need information on the EVB's current status in terms of product health (e.g., Casals et al., 2019; Reinhardt et al., 2019). Thus, the main information category diagnostics, maintenance, and performance allows users to derive information related to (1) EVB health, at the pack, module, and cell level, (2) EVB maintenance history, and (3) EVB delivered performance (see Fig. 8).

The category development employed here was inspired by consulting policymaker publications (European Commission, 2020a), relevant policy initiatives (Circular Economy Initiative Deutschland, 2020), and by reviewing literature related to battery diagnostics and battery second life (e.g., Basia et al., 2021; Canals Casals et al., 2019; Lipu et al., 2018; Ungurean et al., 2017; Xiong et al., 2018).

\subsubsection{Battery health}

To identify EVBs, or rather the respective battery modules qualifying for a second life, information on their state-of-health ( $\mathrm{SoH})$ is needed (Albertsen et al., 2021; Reinhardt et al., 2019). This information is likely to be of benefit to end-of-(first)-life-related actors since it allows them to improve the safety of EVB handling (Bai et al., 2020). Thus, this sub-category allows to derive information on the $\mathrm{SoH}$, state-of-charge (SoC), the depth-of-discharge (DoD), and remaining useful life (RuL) with respect to the cell, module, and pack level. The distinction between cell, module, and pack level was introduced because battery health-related indictors at the cell or module level do not necessarily indicate health at the pack level, and vice versa (Harper et al., 2019).

\subsubsection{Maintenance history}

As EVBs sometimes experience performance-related failures during their use phase, maintenance and repair work needs to be carried out (where possible) (Circular Economy Initiative Deutschland, 2020; Kiemel et al., 2020). Information on such incidents, and their respective triggers, can be of use to prospective buyers or current users of EVs (Beedham, 2021; Evans, 2020). This sub-category is therefore needed to gather information related to past EVB maintenance and repair, and covers the nature of maintenance/repair carried out, the incidents triggering the maintenance/repair work, and the executing party.

\subsubsection{Delivered performance}

Information on an EVB's past performance (e.g., projected lifetime vs. actual duration of use, mileage covered, charging/discharging cycles) may support OEMs and battery designers in their pursuit of improving battery designs (Circular Economy Initiative Deutschland, 2020; Kiemel et al., 2020), and also help EV drivers with respect to their buying-decisions (Beedham, 2021; Evans, 2020). Thus, this sub-category allows one to derive information related to an EVBs performance over its useful lifespan. Such information concerns the driving range covered, dis- and charging cycles, and years of operation.

\subsection{Value chain actors}

The main information category value chain actors allows one to derive information on those who have been involved at any point in time in an EVB's production, handling, use, and end-of-life treatment (see Fig. 9).

The categories shown here were inspired by consulting policymaker publications (European Commission, 2020a), and by reviewing literature focusing on EVBs and critical raw materials (e.g., Mayyas et al.,

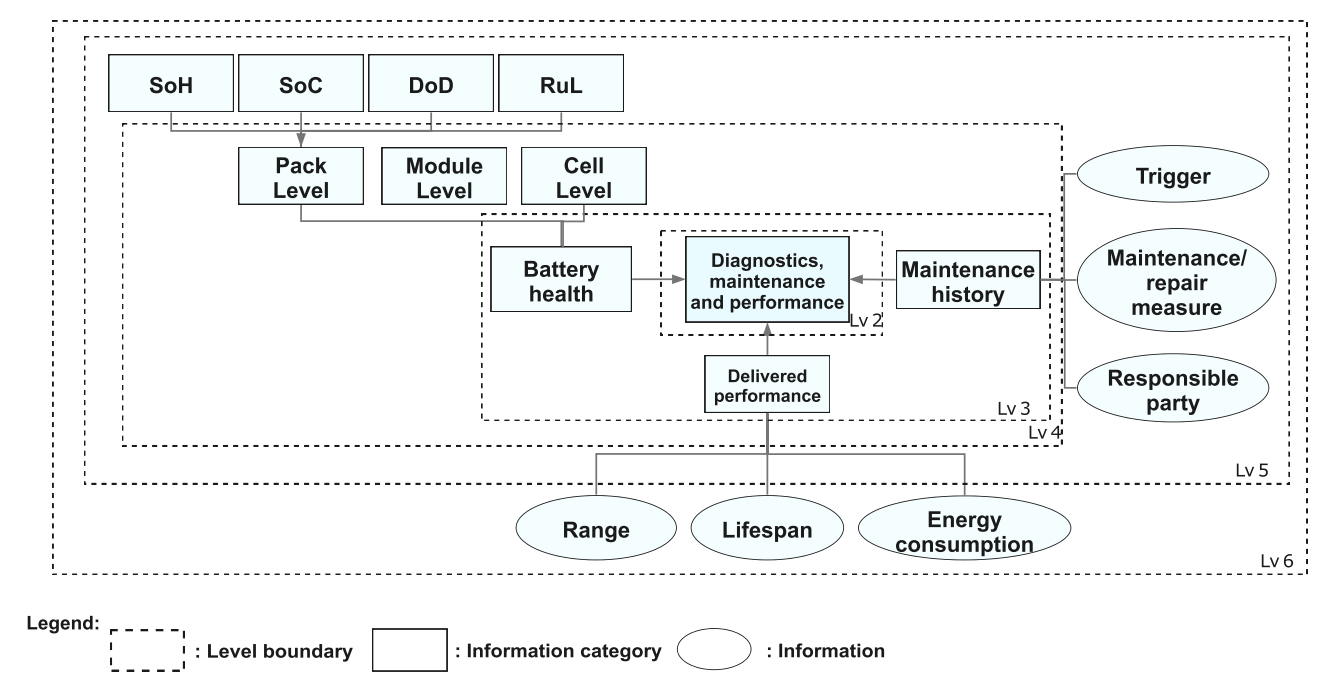

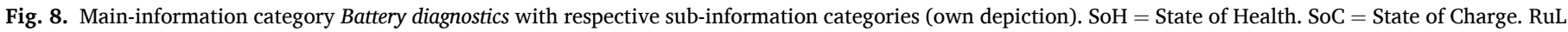
$=$ Remaining useful life. DoD = Depth of Discharge. Lv = level. 


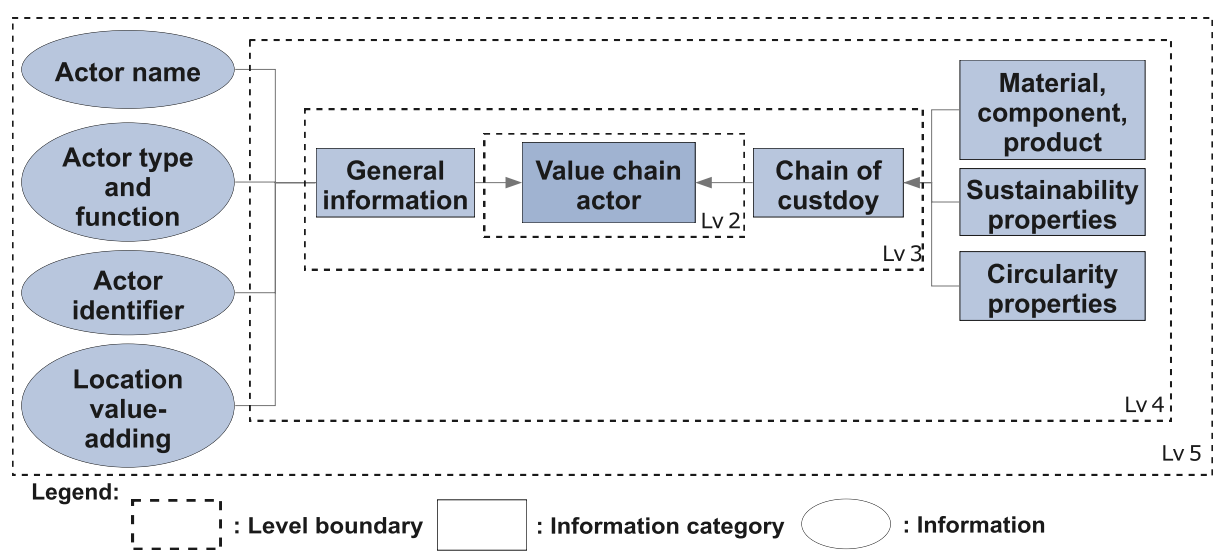

Fig. 9. Main information category value chain actors with respective sub-information categories (own depiction). Lv $=$ level.

2019; Olivetti et al., 2017; Sovacool et al., 2019), and that on digitalization and supply chain management (e.g., Kouhizadeh et al., 2021; Saberi et al., 2019).

Category-related information can be divided into two sub-categories: general actor information and chain of custody. A more detailed description is provided in the following sub-sections.

\subsubsection{General actor information}

As in section 3.1 (Battery), DBP users first require information allowing them to clearly identify value chain stakeholders. Thus, this sub-category allows for the derivation of information on actor name (e. g., company name), actor type and function (e.g., supplier of active material, electrode manufacturer), geographical location of the valueadding activity (e.g., production site of needed components), and identifier (e.g., trade registration number). Such information also serves to enhance transparency along the EVB value chain (Kouhizadeh et al., 2021; Sarkis et al., 2020). However, the concept does not call for personal data (e.g., personal data of EV users).

\subsubsection{Chain of custody}

To further enhance the transparency along the EVB value chain, information on actor responsibilities (i.e., regarding the physical product, and respective sustainability- and circularity-related performance) is also of interest (Circular Economy Initiative Deutschland, 2020; Heinrich and Lang, 2019). Thus, this sub-category allows one to derive information with respect to an EVB's chain of custody, i.e., it enables identification of the point in time when a value chain actors' responsibilities for an EVB (component) started and ended. This concerns actor responsibilities with respect to the physical product, but also those related to sustainability and circularity performance.

\section{Digital battery passport users and their potential use cases}

As we found that the DBP concept described here can be a helpful SPM decision-making tool for various value chain stakeholders (see appendix A, Fig. A1), we now present four use cases in order to illustrate the concept's practical relevance. These are: (1) an OEM (representing the beginning-of-life phase); (2) an EV user (representing the middle-oflife phase); (3) a recycler (representing the end-of-life phase); and (4) a regulatory body (representing a stakeholder group which may exert influence over the entire product life cycle). The use cases were selected because they are able to cover the entire EVB life cycle.

\subsection{OEM: use case "value chain development"}

It is assumed here that the OEM is seeking ways of improving EVB life cycle sustainability and circularity by managing its value chain respectively as a result of mounting regulatory or social pressure (Albertsen et al., 2021; European Commission, 2020a). Thus, OEM use of a DBP is aimed at (1) minimizing negative environmental and social impacts throughout the entire product life cycle, and (2) maximizing EVB circularity performance without compromising sustainability. In order to pursue such aims the OEM requires high-quality and reliable EVB life cycle information (de Oliveira et al., 2021; Ellingsen et al., 2017; Harris et al., 2020; Saidani et al., 2019). This is exactly what our DBP concept is designed to provide. It is further assumed that performance, technical, and safety requirements are prioritized over sustainability and circularity-related requirements (e.g., Chen et al., 2020; Hirz and Brunner, 2015).

The use case "value chain development", presented here, is based on information gained by consulting publications focusing on digitalization in the context of sustainable and/or circular supply chain management (e.g., Bai and Sarkis, 2020; Barykin et al., 2020; Esmaeilian et al., 2020; Ivanov and Dolgui, 2020; Kouhizadeh et al., 2021; Marmolejo-Saucedo and Hartmann, 2020), on product life cycle management (Talkhestani et al., 2018), and on sustainability and the circular economy (Julianelli et al., 2020; Oliveira et al., 2021).

When striving to improve sustainability and circularity within an EVB value chain, the OEM requires clear product-related information in order to identify the EVB of interest. Our DBP concept allows the OEM to access product-related information through the main information category battery, thus allowing the OEM to generate an understanding of the product of interest (see Fig. 4). Subsequently, the OEM requires knowledge about the status quo of the EVB's sustainability and circularity performance, the life cycle hot spots, and the value chain actors involved to identify potential areas of improvement. This information can be derived by accessing the main information category sustainability and circularity (see Fig. 7) and value chain actors (see Fig. 9). Such information allows the OEM to define overall targets in order to see how relevant performance levels may be improved.

\subsection{User EV: use case "the best $E V(B)$ "}

Our second example looks at the case of an EV user, who, while satisfied with the driving performance of the vehicle, is nevertheless in need of reliable, high-quality information on the EVB's sustainability and circularity performance (de Oliveira et al., 2021; Ellingsen et al., 2017; Harris et al., 2020; Saidani et al., 2019). Such a user can benefit from making use of the DBP concept proposed here.

It is assumed that the EV user is looking for an EVB that offers (1) the lowest negative environmental and social impact, and (2) the highest circularity performance possible. In addition, it is assumed, that the EV user prioritizes an EVB that is able to fulfil their needs e.g., concerning driving range, charging time, battery health, etc., prior to taking sustainability and circularity-related performance into consideration (Beedham, 2021; Evans, 2020; Hirz and Brunner, 2015). The use case 
"the best EV(B)" was developed by consulting policymaker publications (European Commission, 2020a), policy initiatives (Circular Economy Initiative Deutschland, 2020), and relevant literature on DMPs (e.g., Heinrich and Lang, 2019; Honic et al., 2019a). In addition, literature on EVBs and their performance (e.g., Chen et al., 2020; Stampatori et al., 2020), blog posts on used EV purchases (e.g., Beedham, 2021; Evans, 2020), and literature on product design (Hirz and Brunner, 2015) also served as a source of inspiration in developing this use case.

First, it is assumed here that the EV user requires general and specific product-related information on the EVB of interest. Such information allows the user to decide which product best matches existing driving needs. Where a used EV is acquired, the EV user requires additional information on the EVB's current battery health status in order to decide whether the $\mathrm{EV}$, or rather, the EVB, is worth considering. In addition, information on maintenance history and mileage covered to date can also be used to support buying decisions. The DBP concept proposed here allows the EV user to access such information through the main information categories battery (see Fig. 6) and battery diagnostics (see Fig. 8). After identifying suitable EVBs, further knowledge concerning EVB sustainability and circularity performance is then required. This information can be derived by accessing the main information category sustainability and circularity (see Fig. 7). To further support the buying decision, EV users may then benefit from information on value chain actors and their respective contributions to aforementioned performances. This can be derived by accessing the main information category value chain actor (see Fig. 9). For additional buying decision support, information relating to EVB (component) origin (e.g., short vs. long product transport routes), or materials employed (e.g., hazardous substances, critical raw materials) may also be of use. Such information can be derived by consulting the main information categories battery (see Fig. 6), sustainability and circularity (see Fig. 7), and value chain actor (see Fig. 9).

\subsection{Recycler: use case "support of recycling efforts"}

The third use case outlined here concerns a recycler and their EVB recycling efforts. At present, recyclers are experiencing difficulties accessing information about battery chemistry, application type, disassembly options, etc. This thus makes EVB recycling efforts rather challenging (Bai et al., 2020). Again, consulting our DBP concept is likely to be of benefit in such cases. As the volume of waste batteries and their disposal is expected to grow rapidly in the near future, it is assumed here that the recyclers is able to offer various recycling pathways (e.g., pyrometallurgical or hydrometallurgical, etc.) (Harper et al., 2019; Mayyas et al., 2019). It is further assumed that the recycler strives to maximize sustainability and circularity performance when considering potential recycling options, and that technical and safety requirements are prioritized rather than sustainability- and circularity-related performance (Harper et al., 2019; Hirz and Brunner, 2015; Mayyas et al., 2019). This use case, "support of recycling efforts", was developed by consulting policymaker literature (European Commission, 2020a), and literature focusing on lithium-ion batteries and recycling (e.g., Bai et al., 2020; Doose et al., 2021; Harper et al., 2019; Mayyas et al., 2019; Velázquez-Martínez et al., 2019).

In order to identify suitable recycling pathways, the recycler is in need of product-related information, such as information concerning battery chemistry (Mayyas et al., 2019). This information can be accessed by consulting the main information category battery (see Fig. 6). In addition, information on any hazardous substances employed can help to ensure safe EVB handling (Bai et al., 2020; Doose et al., 2021; Velázquez-Martínez et al., 2019). This can be accessed by the recycler via the main information categories battery and sustainability and circularity (see Figs. 6 and 7). With respect to ensuring safe work practices and EVB handling, the recycler may further benefit from accessing the main information category diagnostics, maintenance, and performance (see Fig. 8). Relevant information on battery health (e.g., SoC, DoD)
(Doose et al., 2021) is also available here. In addition, the recycler may benefit from our DBP concept by consulting the main information categories battery, and sustainability and circularity (see Figs. 6 and 7) in order to derive information on materials employed, assembly methods (e.g., gluing, welding), and disassembly (Bai et al., 2020).

\subsection{Regulatory body: "facilitating SPM efforts"}

The fourth use case considers a regulatory body and its pursuit of SPM in EVBs, in order to facilitate the transition towards a sustainable circular economy (European Commission, 2020a). It is assumed that the regulatory body has already put the relevant EVB legal requirements into place covering, for example, required environmental performance, mandatory content of secondary material, etc. (European Commission, 2020a). It is further assumed that the regulatory body strives to facilitate SPM efforts by adjusting existing legislation as the need arises. This use case was developed by consulting publicly available policymaker information (European Commission, 2020a), and by reviewing the relevant circular economy policy initiatives (Circular Economy Initiative Deutschland, 2020; Heinrich and Lang, 2019).

When striving to facilitate the transition towards more circular EVB value chains, the regulatory body needs to identify the battery of interest, and thus requires product-related information (e.g., battery application type). This allows the regulator to identify the respective legal requirements. This information can be derived by accessing the main information category battery. Subsequently, the regulatory body is then able to verify whether the battery of interest fulfils legal requirements for market entry purposes by consulting the main information category sustainability and circularity. This enables it to derive information on the battery's sustainability and circularity-related performance. Furthermore, the information content provided by the DBP concept described in the present paper allows the regulatory body to gain an overview of the sustainability and circularity performance of those EVBs currently on the market, and thus enables it to identify relevant development trends. The regulator is thus in a position to check product performance against the established targets (e.g., to assess whether the EVBs currently on the market meet or exceed expectations, or whether EVB manufacturers are struggling to meet legal requirements). Secondly, such information enables the regulatory body to adjust existing legislation (e.g., when defining the legal requirements for market entry), or to develop new regulatory mandates promoting EVB SPM efforts in order to raise their contribution to a sustainable and circular economy.

The practical relevancy of this use case is reflected in the abovementioned developments at the legislative level (European Commission, 2020a) (see section 2.2). Regulatory bodies, such as the EC, are currently implementing regulatory frameworks (e.g., mandating specific carbon footprint thresholds), which will be subject to adjustment over time (European Commission, 2020a). There is thus a clear need for relevant and appropriate information.

\section{Discussion}

The DBP concept proposed here is now examined within the broader context of scientific discussion on circular and sustainable product management and also with respect to its potential implementation. This entails examining the potential use of such a concept for products other than EVBs. This section is structured based on the four information categories proposed above.

\subsection{Product-related information}

The first main information category introduced above was that of battery. The product-related information provided here may be perceived as being the backbone of SPM effort as it facilitates product identification and contextualization (European Commission, 2020a; 
Heinrich and Lang, 2019). This then allows DBP users to improve understanding of the product and to proceed with the respective SPM effort. Any lack of proper product identification and contextualization is likely to impair the quality of essential decision-making among value chain stakeholders. By providing the requisite context and background information, use of a DBP enables stakeholders to proceed more confidently with their SPM activities.

At a minimum, a DBP must provide general product-related information (European Commission, 2020a; Heinrich and Lang, 2019), e.g., relating to product type, intended form of application, a unique identifier in the form of a serial or batch number, and origin (Heinrich and Lang, 2019). In the case of EVBs this can be translated into information concerning battery type (e.g., for an EV, energy storage application), battery chemistry, and battery identifier (e.g., serial number, batch number) (Circular Economy Initiative Deutschland, 2020; Coffin and Horowitz, 2018; Ellingsen et al., 2014; Jussani et al., 2017; Kiemel et al., 2020). Further information may also be required in order to take greater account of the decision-maker context. This could include more specific product-related information, such as information on respective product performance, function and composition (Heinrich and Lang, 2019). In the case of EVBs, this might take the form of information on battery performance-related properties (e.g., driving range, lifespan), electrical engineering-related specifications (e.g., energy density, power density), and the EVB's structure with respect to cell, module, and pack level (e.g., number total cells and modules, employed assembly processes) (Chen et al., 2020; Cusenza et al., 2019; Doose et al., 2021; Stampatori et al., 2020).

The need for product-related information can also be derived from in the DMP literature (Heinrich and Lang, 2019; Honic et al., 2019a, 2019c), and in the sustainability and circularity assessment-related literature (Elia et al., 2017; Ellingsen et al., 2017; Saidani et al., 2019). Non-governmental institutions (CEWI, 2021) found such information to be relevant as well. However, their focus was placed on information related to employed materials only, which we argue to be just a fraction of needed information due to aforementioned reasons (i.e., product identification, contextualization). In general, it can be argued that such information is needed for any kind of DPP. However, depending on the product of interest, the content of the information category might require adjustments.

In practice, most product-related information should be readily available as it is often required by existing regulations (e.g., in the form product specification sheets) (European Commission, 2020a). However, in some cases stakeholders may be reluctant to disclose or share data, or there may be a lack of appropriate incentives (de Oliveira et al., 2021; Saberi et al., 2019). This concerns, for example, EVB chemistry, a key factor in battery performance, and one demanding a high level of investment (Mayyas et al., 2019). Value chain stakeholders in possession of proprietary knowledge (e.g., the OEMs with detailed knowledge of battery composition) are likely to be wary of sharing any information which might lead to a competitive disadvantage (Kiemel et al., 2020). To stimulate the provision of such data as part of an EVB value chain, stakeholders may thus need to be offered various economic or regulatory incentives (Esmaeilian et al., 2020; Honic et al., 2019c). The exact nature of the incentives needed to stimulate greater stakeholder collaboration thus remains a subject of considerable interest (Esmaeilian et al., 2020).

Regarding data properties, most of the requisite product-related data is likely to be static in nature (Circular Economy Initiative Deutschland, 2020), and it would thus only need to be provided once over the entire EVB life cycle.

\subsection{Sustainability and circularity-related information}

The second information category presented here is the category sustainability and circularity. This pertains to those aspects of EVB properties and performance related to sustainability and circularity.
While purely product-related information may be perceived as providing the contextual backbone of a DBP, this remains somewhat superficial and inadequate, an empty exercise in labelling, without further detail concerning product sustainability and circularity performance. In the context of SPM, the provision of such information is essential for proper application of a DBP (Ellingsen et al., 2017; Heinrich and Lang, 2019; Honic et al., 2019a, 2019c; Saidani et al., 2019). The distinction between sustainability and circularity-related information can be justified, due to circularity not necessarily implying sustainability (de Oliveira et al., 2021; Harris et al., 2020; Kirchherr et al., 2017), hence circularity performance-related indicators not necessarily being able to contribute to a comprehensive product sustainability assessment. With respect to sustainability, we want to stress again, the importance of taking environmental and social sustainability into consideration. Some DBP-related grey literature (CEWI, 2021) just focus on the environmental perspective, which we argue to be a too narrow perspective for comprehensive sustainability assessments and considerations. With respect to indicators, the concept proposed here suggests that in order to provide a meaningful metric with respect to sustainability and circularity-related performance, a DPB needs to make use of several indicators (de Oliveira et al., 2021; Harris et al., 2020; Saidani et al., 2019) as use of a single indicator is likely to lead to distortion or bias when measuring performance, and may fail to do justice to the complexities involved (de Oliveira et al., 2021; Harris et al., 2020; Saidani et al., 2019). For example, it is quite possible that performance may appear to improve when measured by one indicator, yet in reality, overall sustainability and circularity performance continue to decline. In practice, which particular indicator set is needed, will depend on the specific needs and context of the DBP user, i.e. on their position within the respective product life cycle (de Oliveira et al., 2021; Saidani et al., 2019). For example, beginning-of-life-related decision-makers are most likely to be interested in those indicators required by regulatory mandates (e.g., those designed to ascertain carbon footprint) (European Commission, 2020a). However, other value chain actors, such as EV users, might require other indicators (e.g., those used to measure the extent of forced labor, child labor, etc.) in order to derive meaningful information.

A DBP should provide its users, at the least, with information on the status quo of sustainability and circularity-related performance, and information on the performance achieved during the EVB's entire life cycle (i.e., from the beginning-of-life up to the end-of-life) so that relevant life cycle hotspots may be identified (Circular Economy Initiative Deutschland, 2020). This helps users identify areas of potential improvement, establish suitable sustainability and circularity targets, and define the respective strategies needed to attain said targets (de Oliveira et al., 2021; Saidani et al., 2019). As digital technologies (e.g., digital twin) play a key role in DBP application, it is hoped DBPs will also provide users with real-time data-based estimates concerning the sustainability and circularity-related impact of different decision pathways (Jones et al., 2020), counteracting the current lack of high-quality data (Kayikci et al., 2021; Kouhizadeh et al., 2021). For example, an end-of-life actor would then be in a position to check whether the value chain loop-closing pathway "second battery life" is more favorable than recycling, in terms of sustainability and circularity-related performance. Battery designers could also benefit from such estimates as they would then be able to incorporate sustainability and circularity-related considerations into the battery design process. Thus, if used to their full potential, DBPs could become a powerful support tool in SPM. A DBP could also fulfill several functions simultaneously. It could be a unique product identifier, a valuable data source to support SPM efforts, and a means of assessing sustainability- and circularity-related performance (see Fig. 10). However, as this might also generate greater complexity when unchecked (Esmaeilian et al., 2020), it is also likely to make implementation effort more challenging.

It can be further argued that additional information is needed to give sustainability and circularity performance more meaning, e.g., in order 


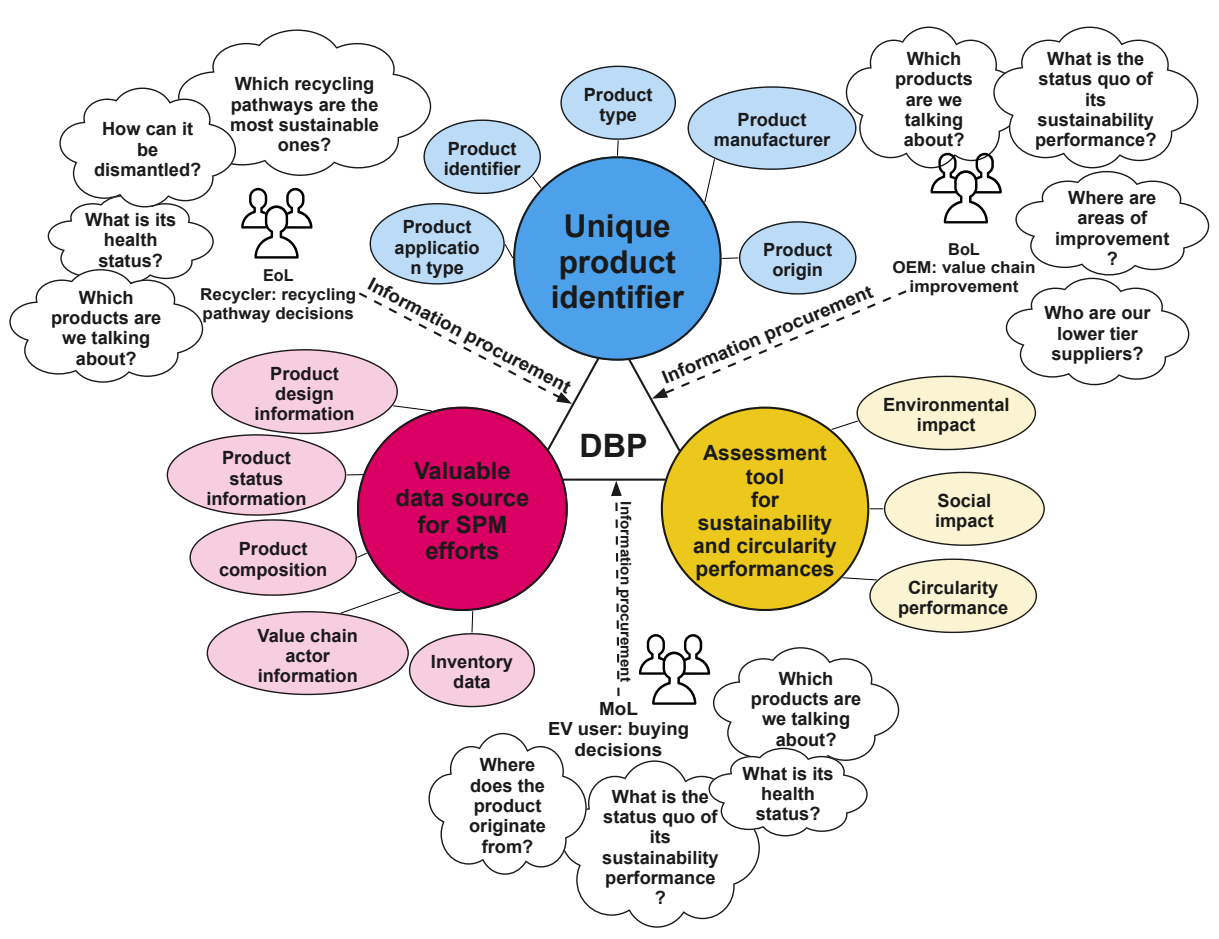

Fig. 10. Functions of the DBP concept as presented in the present paper (own depiction). DBP = digital battery passport. SPM $=$ Sustainable product management. $\mathrm{BoL}=$ beginning-of-life. $\mathrm{MoL}=$ middle-of-life. $\mathrm{EoL}=$ end-of-life.

to cover the precise nature of metrics, categories used, assessment standards, areas of application, etc. When this is used to enhance user understanding it not only generates greater transparency (and thus user confidence) (Esmaeilian et al., 2020), it also serves to improve the quality of decision-making (Ellingsen et al., 2017; Saidani et al., 2019).

This information category is further of interest for DPPs in general, as the importance of corresponding information concerns not only EVBs.

\subsection{Product status-related information}

The third information category presented above was diagnostics, maintenance, and delivered performance. This provides information concerning an EVB's status in terms of it being still suitable for its intended application (i.e., in an EV), for a less energy demanding one (i.e., second life) in case of having reached its end-of-life, or for none (i.e., recycling case) (Reinhardt et al., 2019). Such information may indicate that it may be possible to pursue value chain loop-closing pathways other than recycling, namely repair, repurpose, or reuse (e.g., Albertsen et al., 2021; Circular Economy Initiative Deutschland, 2020; Kiemel et al., 2020; Reinhardt et al., 2019; Wrålsen et al., 2021). In the case of an EVB, this is translated into information on battery health (Albertsen et al., 2021; Reinhardt et al., 2019). Hence, DBP users, in particular those in end-of-(first)-life-related activities, would clearly benefit. Other EVB diagnostic-related indicators (e.g., SoC, DoD) are also of interest as they may help improve the safety of battery handling activities, in particular for end-of-(first)-life-related value chain actors (Bai et al., 2020). Information on product status may also cover maintenance history and maintenance work triggering incidents, as well past product performance and expected life. Regarding DPPs in general, it makes sense to incorporate information about the product health. However, how product health is expressed depends on the product of interest and has to be accordingly defined for each product.

Product status-related information, paired with sustainability and circularity-related information, has the potential to create a powerful foundation for SPM-related decisions. Once employed in its full scope of applications, a DBP can become a powerful instrument for estimating the sustainability and circularity of available value chain loop-closing pathways. However, as indicated above, it needs to be kept in mind that stakeholders may opt to adopt less sustainable value chain loopclosing pathways, depending on perceived incentives. For example, even when an EVB qualifies for a second life application, and even when this would improve sustainability, the respective decision-makers might still opt for sending the EVB straight to recycling. An interplay of several factors is at work here and such decisions may depend on changes in demand or market conditions, or on changes in EVB regulation regarding recycling or reuse of secondary materials (European Commission, 2020a; Mayyas et al., 2019).

With respect to data availability, EVB health-related information can be found on an EVB's respective battery management system (BMS) (Basia et al., 2021). Thus, it would be of interest to have an interface between a BMS and a DBP which enables the exchange of battery health-related data. Potential DBP-enabling technologies, such as the digital twin, have the potential to collect and store the real-time data of their physical counterpart (Jones et al., 2020). Thus, data is updated as soon as new data is made available. This could, for example, help establish more predictive maintenance (Jones et al., 2020). However, as battery status changes rather quickly over time (Basia et al., 2021), and as EVBs have an average useful lifespan of eight years (Kiemel et al., 2020), massive volumes of battery status-related data would be available. This could pose quite a challenge when it comes to data collection, processing (Jones et al., 2020), and storage (Esmaeilian et al., 2020), and is further likely to increase the complexity of DBP application (Jones et al., 2020). Despite these possible challenges, battery status information still remains attractive, and could be provided via time-stamped log entries (i.e., data being updated in regular intervals such as annual vehicle check-ups) (Saberi et al., 2019).

\subsection{Value chain actor-related information}

The fourth information category presented above was value chain actors. This covers information on the various actors involved over an EVB's life cycle, and may thus serve to enhance value chain transparency. Enhanced value chain transparency is also one of the benefits attributed to DPPs (Circular Economy Initiative Deutschland, 2020; 
Heinrich and Lang, 2019). For transparency enhancement purposes basic value chain actor-related information, such as actor name, actor type, actor location and function, and a unique identifier in the form of a trade registration number, is all of considerable interest. While such information may currently be readily available with respect to top tier suppliers, (e.g., OEMs need to know who their top tier suppliers are), this may not be the case when it comes to low tier suppliers due to lack of supply chain traceability and transparency. In addition, some value chain actors might not perceive enhanced value chain transparency as a benefit, but rather as a form of competitive disadvantage.

Furthermore, the DBP concept presented here suggests that chain of custody-related information could be used to make product-related responsibilities more visible (Kouhizadeh et al., 2021), compared to other grey literature on DPPs (e.g., CEWI, 2021). Grey literature emphasizes for example the need for value chain transparency via monitoring (e.g., in terms of greenhouse gas emissions) (CEWI, 2021). However, chain of custody-related information is not explicitly mentioned, but in our opinion needed because of aforementioned arguments.

Chain of custody-related information paired with sustainability and circularity-related information could again provide a powerful foundation for decision-making (Saberi et al., 2019). In such a case a DBP could provide its users with more in-depth information about value chain actors' responsibilities, particularly those related to an EVB's sustainability and circularity performance. Such information could enable OEMs to pursue sustainable and circular value chain development efforts, thus allowing for the identification of those value chain stakeholders who contribute the most to such performance, and also enabling stakeholders to identify potential areas of improvement (Kouhizadeh et al., 2021). While this is of interest from a sustainability, and accountability perspective, it is also likely that value chain actors will be reluctant to share such data since it might expose them to criticism (e.g., from visibly "greener" competitors, consumers) and thus lead to loss of reputation (Kouhizadeh et al., 2021).

\section{Conclusions, implications, and future research}

The present paper has presented the conceptual basis for use of a DBP in the field of EVBs, and has attempted to outline the numerous informational requirements of the value chain stakeholders involved. Specifically, four use cases, describing distinct value chain stakeholders, were drawn upon in order to illustrate how the concept may be applied to support SPM.

\subsection{Theoretical implications}

Compared to existing DPP research, this paper has set out to provide (for the first time, to the authors' knowledge), a definition of a DBP in terms of the information needs and requirements in the context of SPM. This allows to further facilitate DPP debate amongst scholars, which may serve to further build upon the concept provided in this paper, as well as further explore DPP potentials in an SPM context from a scientific perspective. In addition, the illustrated mixed methods approach for the development of the DBP concept presented in this paper may further serve as theoretical groundwork in developing conceptual DPPs for other products, and thus help support related SPM efforts in several fields.

\subsection{Practical implications}

A DBP is often referred to by policymakers as a form of unique product identifier. However, as developed here, and by making use of appropriate data, such a DBP can also become a valuable data source in pursuing SPM in the context of a circular economy. By specifically taking various sustainability aspects into consideration, our DBP concept goes beyond the requirements of the new battery directive recently proposed by the EC. The presented DBP concept can be further viewed as an alternative to DBP development driven by policymakers, and the industrial environment. It thus provides policymakers with guidance when it comes to defining the scope of DBPs, as well as DPPs in an SPM context. Our work also provides further guidance for policymakers concerning how sustainability and circular economy-related aspects may be treated more comprehensively in the context of digitalization. As this DBP proposal calls for in-use data (e.g., battery diagnostics-related information), it calls for unleashing the full potential of digital technologies. It thus contributes to a vision of a digital SPM.

Present DBP technology remains relatively immature, resulting in a lack of technical DBP implementation. As a result, DBP conceptualization is needed, both from a scientific and an industry perspective. Hence, the presented concept servers as first conceptualization effort from a scientific perspective, which can and should be discussed by the scientific community and industry. This allows to combine the best of both worlds, culminating in a powerful and practical tool for SPM support.

\subsection{Limitations}

The present work remains rather theoretical as it is mostly based on desk research. Even though preliminary expert validation has been carried out, it needs to be noted that the concept at hand has been developed on the assumption that the requisite data is readily available and accessible.

\subsection{Outlook for future research}

Further research will entail seeking further expert validation, improving understanding with respect to data availability and accessibility, and more detailed analysis of the functions a DBP may fulfil in the context of SPM. In addition, the appropriate data types (e.g., static, dynamic, real-time), as well as those factors needed for successful DBP implementation (i.e., drivers, enablers, and barriers) all need to be identified. This will serve to greatly improve overall understanding and thus, it is hoped, help facilitate DBP implementation and adoption.

\section{CRediT authorship contribution statement}

Katharina Berger: Methodology, Investigation, Data curation, Writing - original draft, Writing - review \& editing, Visualization. Josef-Peter Schöggl: Conceptualization, Methodology, Writing - review \& editing, Funding acquisition. Rupert J. Baumgartner: Supervision, Conceptualization, Methodology, Writing - review \& editing, Funding acquisition, Project administration.

\section{Declaration of competing interest}

The authors declare that they have no competing financial interests or personal relationships that may have influenced the work reported in this paper.

\section{Acknowledgments}

The financial support of the Austrian Federal Ministry for Digital and Economic Affairs, the National Foundation for Research, Technology and Development, the University of Graz and the Christian Doppler Research Association is gratefully acknowledged.

\section{Appendix A. Supplementary data}

Supplementary data to this article can be found online at https://doi. org/10.1016/j.jclepro.2022.131492. 


\section{References}

Adisorn, T., Tholen, L., Götz, T., 2021. Towards a digital product passport fit for contributing to a circular economy. Energies 14. https://doi.org/10.1007/s40314014-0179-y.

Alamerew, Y.A., Brissaud, D., 2020. Modelling reverse supply chain through system dynamics for realizing the transition towards the circular economy: a case study on electric vehicle batteries. J. Clean. Prod. 254, 120025 https://doi.org/10.1016/j. jclepro.2020.120025.

Albertsen, L., Richter, J.L., Peck, P., Dalhammar, C., Plepys, A., 2021. Circular business models for electric vehicle lithium-ion batteries: an analysis of current practices of vehicle manufacturers and policies in the EU. Resour. Conserv. Recycl. 172, 105658 https://doi.org/10.1016/j.resconrec.2021.105658.

Bag, S., Gupta, S., Kumar, S., 2021. Industry 4.0 adoption and 10R advance manufacturing capabilities for sustainable development. Int. J. Prod. Econ. 231, 107844 https://doi.org/10.1016/j.ijpe.2020.107844.

Bai, C., Sarkis, J., 2020. A supply chain transparency and sustainability technology appraisal model for blockchain technology. Int. J. Prod. Res. 58, 2142-2162. https://doi.org/10.1080/00207543.2019.1708989.

Bai, Y., Muralidharan, N., Sun, Y.K., Passerini, S., Stanley Whittingham, M., Belharouak, I., 2020. Energy and environmental aspects in recycling lithium-ion batteries: concept of battery identity global passport. Mater. Today 41, 304-315. https://doi.org/10.1016/j.mattod.2020.09.001.

Barykin, S.Y., Bochkarev, A.A., Kalinina, O.V., Yadykin, V.K., 2020. Concept for a supply chain digital twin. Int. J. Math. Eng. Manag. Sci. 5, 1498-1515. https://doi.org/ 10.33889/IJMEMS.2020.5.6.111.

Basia, A., Simeu-Abazi, Z., Gascard, E., Zwolinski, P., 2021. Review on State of Health estimation methodologies for lithium-ion batteries in the context of circular economy. CIRP J. Manuf. Sci. Technol. 32, 517-528. https://doi.org/10.1016/j. cirpj.2021.02.004

Batista, L., Bourlakis, M., Smart, P., Maull, R., 2018. In search of a circular supply chain archetype-a content-analysis-based literature review. Prod. Plann. Control 29, 438-451. https://doi.org/10.1080/09537287.2017.1343502.

Beedham, M., 2021. Buying a Second-Hand EV? Do These 5 Things First. https://th enextweb.com/news/buying-a-second-hand-ev-do-these-5-things-first. (Accessed 12 January 2021)

Birkel, H., Müller, J.M., 2021. Potentials of industry 4.0 for supply chain management within the triple bottom line of sustainability - a systematic literature review. J. Clean. Prod. 289, 125612 https://doi.org/10.1016/j.jclepro.2020.125612.

BMW Group, 2019. Sustainable Value Report 2019. https://www.bmwgroup.com/conte nt/dam/grpw/websites/bmwgroup com/responsibility/downloads/en/2020/2020 -BMW-Group-SVR-2019-Englisch.pdf. (Accessed 1 December 2021).

Bobba, S., Mathieux, F., Ardente, F., Blengini, G.A., Cusenza, M.A., Podias, A., Pfrang, A., 2018. Life Cycle Assessment of repurposed electric vehicle batteries: an adapted method based on modelling energy flows. J. Energy Storage 19, 213-225. https:// doi.org/10.1016/j.est.2018.07.008.

Bundesministerium für Wirtschaft und Energie, 2020. BMWi - Automobilindustrie. https ://www.bmwi.de/Redaktion/DE/Textsammlungen/Branchenfokus/Industrie/bran chenfokus-automobilindustrie.html. (Accessed 1 December 2021).

Buruzs, A., Torma, A., 2017. A review on the outlook of the circular economy in the automotive industry. Int. J. Environ. Ecol. Eng. 11, 576-580. https://doi.org/ 10.5281/zenodo.1316081.

Canals Casals, L., Barbero, M., Corchero, C., 2019. Reused second life batteries for aggregated demand response services. J. Clean. Prod. 212, 99-108. https://doi.org/ 10.1016/j.jclepro.2018.12.005

Casals, L.C., García, B.A., Canal, C., 2019. Second life batteries lifespan : rest of useful life and environmental analysis. J. Environ. Manag. 232, 354-363. https://doi.org/ 10.1016/j.jenvman.2018.11.046.

CEWI, 2021. Digitaler Produktpass für Klima- und Ressourcenschutz. Praxischeck aus der Automobilindustrie als Beitrag zu den Koalitionsverhandlungen der neuen Legislaturperiode. https://klimawirtschaft.org/praxischeck-digitaler-produkt pass-7300. (Accessed 1 December 2021)

Chen, R., Li, Q., Yu, X., Chen, L., Li, H., 2020. Approaching practically accessible solidstate batteries. Stabil. Issues Relat. Solid Electrolyt. Interfaces 120, 6820-6877. https://doi.org/10.1021/acs.chemrev.9b00268.

Circular Economy Initiative Deutschland, 2020. Ressourcen- schonende Batteriekreisläufe. https://www.circular-economy-initiative.de/publikationen. (Accessed 1 December 2021).

Circulor, 2021. Battery Passport | Circulor. https://www.circulor.com/battery-passport. (Accessed 1 December 2021).

Coffin, D., Horowitz, J., 2018. The supply chain for electric vehicle batteries the supply chain for electric vehicle batteries Journal of international Commerce and economics 2. J. Int. Commer. Econ. 1-21.

Cusenza, M.A., Bobba, S., Ardente, F., Cellura, M., Di Persio, F., 2019. Energy and environmental assessment of a traction lithium-ion battery pack for plug-in hybrid electric vehicles. J. Clean. Prod. 215, 634-649. https://doi.org/10.1016/j. jclepro.2019.01.056.

de Oliveira, C.T., Dantas, T.E.T., Soares, S.R., 2021. Nano and micro level circular economy indicators: assisting decision-makers in circularity assessments. Sustain. Prod. Consum. 26, 455-468. https://doi.org/10.1016/j.spc.2020.11.024.

Doose, S., Mayer, J.K., Michalowski, P., Kwade, A., 2021. Challenges in ecofriendly battery recycling and closed material cycles : a perspective on future lithium battery generations. Metals (Basel) 11, 291. https://doi.org/10.3390/met11020291.

Elia, V., Gnoni, M.G., Tornese, F., 2017. Measuring circular economy strategies through index methods: a critical analysis. J. Clean. Prod. 142, 2741-2751. https://doi.org/ 10.1016/j.jclepro.2016.10.196.
Ellingsen, L.A.W., Hung, C.R., Strømman, A.H., 2017. Identifying key assumptions and differences in life cycle assessment studies of lithium-ion traction batteries with focus on greenhouse gas emissions. Transport. Res. Transport Environ. 55, 82-90. https://doi.org/10.1016/j.trd.2017.06.028.

Ellingsen, L.A.W., Majeau-Bettez, G., Singh, B., Srivastava, A.K., Valøen, L.O., Strømman, A.H., 2014. Life cycle assessment of a lithium-ion battery vehicle pack. J. Ind. Ecol. 18, 113-124. https://doi.org/10.1111/jiec.12072.

Esmaeilian, B., Sarkis, J., Lewis, K., Behdad, S., 2020. Blockchain for the future of sustainable supply chain management in Industry 4.0. Resour. Conserv. Recycl. 163, 105064 https://doi.org/10.1016/j.resconrec.2020.105064.

European Commission, 2020a. Proposal For A Regulation of the European Parliamnet and of the Council Concerning Batteries And Waste Batteries, Repealing Directive 2006/66/EC and Amending Regulation (EU) No 2019/1020. https://eur-lex.europa. eu/legal-content/EN/TXT/?uri=CELEX\%3A52020PC0798. (Accessed 1 December 2021).

European Commission, 2020b. Circular Economy Action Plan. For A Cleaner And More Competitive Europe. https://ec.europa.eu/environment/pdf/circular-economy/n ew_circular_economy_action_plan.pdf. (Accessed 1 December 2021).

Evans, J., 2020. Used EV Guide: How To Buy A Second-Hand Electric Car | Autocar. https://www.autocar.co.uk/car-news/features/used-ev-guide-how-buy-second-han d-electric-car. (Accessed 1 December 2021).

Ferguson, G., 2011. English as an international language of scientific publication : a study of attitudes. World Englishes 30, 41-59. https://doi.org/10.1111/j.1467971X.2010.01656.x.

Fritz, M.M.C., Rauter, R., Baumgartner, R.J., Dentchev, N., 2018. A supply chain perspective of stakeholder identification as a tool for responsible policy and decision-making. Environ. Sci. Pol. 81, 63-76. https://doi.org/10.1016/j. envsci.2017.12.011.

Garrido-Hidalgo, C., Ramirez, F.J., Olivares, T., Roda-Sanchez, L., 2020. The adoption of Internet of Things in a Circular Supply Chain framework for the recovery of WEEE: the case of Lithium-ion electric vehicle battery packs. Waste Manag. 103, 32-44. https://doi.org/10.1016/j.wasman.2019.09.045.

Geissdoerfer, M., Savaget, P., Bocken, N.M.P., Hultink, E.J., 2017. The Circular Economy - a new sustainability paradigm? J. Clean. Prod. 143, 757-768. https://doi.org/ 10.1016/j.jclepro.2016.12.048.

Gligoric, N., Krco, S., Hakola, L., Vehmas, K., De, S., Moessner, K., Jansson, K., Polenz, I., Van Kranenburg, R., 2019. Smarttags: IoT product passport for circular economy based on printed sensors and unique item-level identifiers. Sensors (Switzerland) 19. https://doi.org/10.3390/s19030586.

Global Battery Alliance, 2020. The global battery alliance battery passport: giving an identity to the EV's most important component. Glob. Batter. Alliance. https://www. globalbattery.org/battery-passport/. (Accessed 1 December 2021).

Haddaway, N.R., Bayliss, H.R., 2015. Shades of grey: two forms of grey literature important for reviews in conservation. Biol. Conserv. 191, 827-829. https://doi.org/ 10.1016/j.biocon.2015.08.018.

Harper, G., Sommerville, R., Kendrick, E., Driscoll, L., Slater, P., Stolkin, R., Walton, A., Christensen, P., Heidrich, O., Lambert, S., Abbot, A., Ryder, K., Gains, L., Anderson, P., 2019. Recycling lithium-ion batteries from electric vehicles. Nature 575, 75-86. https://doi.org/10.1038/s41586-019-1682-5.

Harris, S., Martin, M., Diener, D., 2020. Circularity for circularity's sake? Scoping review of assessment methods for environmental performance in the circular economy. Sustain. Prod. Consum. 26, 172-186. https://doi.org/10.1016/j.spc.2020.09.018.

Heinrich, M., Lang, W., 2019. Materials Passports - Best Practice. https://www.ba mb2020.eu/wp-content/uploads/2019/02/BAMB_MaterialsPassports_BestPractice. pdf. (Accessed 1 December 2021).

Hirz, M., Brunner, H., 2015. ECO-design in the automotive industry - potentials and challenges. In: Paper Presented at MOSTOP 2015. Brela, Croatia.

Honic, M., Kovacic, I., Aschenbrenner, P., Ragossnig, A., 2021. Material Passports for the end-of-life stage of buildings: challenges and potentials. J. Clean. Prod. 319, 128702 https://doi.org/10.1016/j.jclepro.2021.128702.

Honic, M., Kovacic, I., Rechberger, H., 2019a. Improving the recycling potential of buildings through Material Passports (MP): an Austrian case study. J. Clean. Prod. 217, 787-797. https://doi.org/10.1016/j.jclepro.2019.01.212.

Honic, M., Kovacic, I., Rechberger, H., 2019b. Concept for a BIM-based material passport for buildings. IOP Conf. Ser. Earth Environ. Sci. 225 https://doi.org/10.1088/17551315/225/1/012073.

Honic, M., Kovacic, I., Sibenik, G., Rechberger, H., 2019c. Data- and stakeholder management framework for the implementation of BIM-based Material Passports. J. Build. Eng. 23, 341-350. https://doi.org/10.1016/j.jobe.2019.01.017.

Hua, Y., Liu, X., Zhou, S., Huang, Y., Ling, H., Yang, S., 2020. Toward sustainable reuse of retired lithium-ion batteries from electric vehicles. Resour. Conserv. Recycl. 168, 105249 https://doi.org/10.1016/j.resconrec. 2020.105249.

Ivanov, D., Dolgui, A., 2020. A digital supply chain twin for managing the disruption risks and resilience in the era of Industry 4.0. Prod. Plann. Control 32, 775-788. https://doi.org/10.1080/09537287.2020.1768450.

Jones, D., Snider, C., Nassehi, A., Yon, J., Hicks, B., 2020. Characterising the Digital Twin: a systematic literature review. CIRP J. Manuf. Sci. Technol. 29, 36-52. https://doi.org/10.1016/j.cirpj.2020.02.002.

Julianelli, V., Caiado, R.G.G., Scavarda, L.F., Cruz, S.P. de M.F., 2020. Interplay between reverse logistics and circular economy: critical success factors-based taxonomy and framework. Resour. Conserv. Recycl. 158, 104784 https://doi.org/10.1016/j. resconrec.2020.104784.

Jussani, A.C., Coulter Wright, J.T., Motomatsu, R.K., 2017. Battery global value chain and its technological opportunities for electric vehicle in Brazil. EVS 2017 - 30th Int. Electr. Veh. Symp. Exhib. 14, 333-338. 
Kayikci, Y., Kazancoglu, Y., Lafci, C., Gozacan, N., 2021. Exploring barriers to smart and sustainable circular economy: the case of an automotive eco-cluster. J. Clean. Prod. 314 https://doi.org/10.1016/j.jclepro.2021.127920.

Kiemel, S., Koller, J., Kaus, D., Singh, S., Full, J., Weeber, M., Miehe, R., 2020. Untersuchung : Kreislaufstrategien für Batteriesysteme in Baden-Württemberg. https://www.ipa.fraunhofer.de/de/referenzprojekte/KSBS.html. (Accessed 1 December 2021).

Kirchherr, J., Reike, D., Hekkert, M., 2017. Conceptualizing the circular economy: an analysis of 114 definitions. Resour. Conserv. Recycl. 127, 221-232. https://doi.org/ 10.1016/j.resconrec.2017.09.005.

Kouhizadeh, M., Saberi, S., Sarkis, J., 2021. Blockchain technology and the sustainable supply chain: theoretically exploring adoption barriers. Int. J. Prod. Econ. 231, 107831 https://doi.org/10.1016/j.ijpe.2020.107831.

Kumar, P., Singh, R.K., Kumar, V., 2021. Managing supply chains for sustainable operations in the era of industry 4.0 and circular economy: analysis of barriers. Resour. Conserv. Recycl. 164, 105215 https://doi.org/10.1016/j. resconrec.2020.105215.

Lipu, M.S.H., Hannan, M.A., Hussain, A., Hoque, M.M., Ker, P.J., Saad, M.H.M., Ayob, A., 2018. A review of state of health and remaining useful life estimation methods for lithium-ion battery in electric vehicles: challenges and recommendations. J. Clean. Prod. 205, 115-133. https://doi.org/10.1016/j.jclepro.2018.09.065.

Luscuere, L.M., 2017. Materials Passports: optimising value recovery from materials. Proc. Inst. Civ. Eng. Waste Resour. Manag. 170, 25-28. https://doi.org/10.1680/ jwarm.16.00016.

Marmolejo-Saucedo, J.A., Hartmann, S., 2020. Trends in digitization of the supply chain: a brief literature review. EAI Endorsed Trans. Energy Web 7, 1-7. https://doi.org/ 10.4108/EAI.13-7-2018.164113.

Mayyas, A., Steward, D., Mann, M., 2019. The case for recycling: overview and challenges in the material supply chain for automotive li-ion batteries. Sustain. Mater. Technol. 19, e00087 https://doi.org/10.1016/j.susmat.2018.e00087.

Millar, N., McLaughlin, E., Börger, T., 2019. The circular economy: swings and roundabouts? Ecol. Econ. 158, 11-19. https://doi.org/10.1016/j. ecolecon.2018.12.012.

Moher, D., Liberati, A., Tetzlaff, J., Altman, D.G., 2009. Preferred reporting items for systematic reviews and meta-analyses: the PRISMA statement. PLoS Med. 6, b2535 https://doi.org/10.1136/bmj.b2535.

Nissan Motor Corporation, 2019. Sustainability Report 2019. https://www.nissanglobal.com/EN/DOCUMENT/PDF/SR/2019/SR19_E_All.pdf. (Accessed 1 December 2021).

Okoli, C., Pawlowski, S.D., 2004. The Delphi method as a research tool : an example, design considerations and applications. Inf. Manag. 42, 15-29. https://doi.org/ 10.1016/j.im.2003.11.002.

Oliveira, M., Miguel, M., van Langen, S.K., Ncube, A., Zucaro, A., Fiorentino, G., Passaro, R., Santagata, R., Coleman, N., Lowe, B.H., Ulgiati, S., Genovese, A., 2021. Circular economy and the transition to a sustainable society: integrated assessment methods for a new paradigm. Circ. Econ. Sustain. 1, 99-113. https://doi.org/ 10.1007/s43615-021-00019-y.

Olivetti, E.A., Ceder, G., Gaustad, G.G., Fu, X., 2017. Lithium-ion battery supply chain considerations: analysis of potential bottlenecks in critical metals. Joule 1, 229-243. https://doi.org/10.1016/j.joule.2017.08.019.

Parchomenko, A., Nelen, D., Gillabel, J., Rechberger, H., 2019. Measuring the circular economy - a multiple correspondence analysis of 63 metrics. J. Clean. Prod. 210, 200-216. https://doi.org/10.1016/j.jclepro.2018.10.357.

Philippot, M., Alvarez, G., Ayerbe, E., Mierlo, J. Van, 2019. Eco-efficiency of a lithiumion battery for electric vehicles : influence of manufacturing country and commodity prices on GHG emissions and costs. Batteries 5. https://doi.org/10.3390/ batteries5010023.

Portillo-Barco, C., Charnley, F., 2015. Data requirements and assessment of technologies enabling a product passport within products exposed to harsh environments: a case study of a high pressure nozzle guide vane. Int. J. Prod. Lifecycle Manag. 8, 253-282. https://doi.org/10.1504/IJPLM.2015.074145.

Rafele, C., Mangano, G., Cagliano, A.C., Carlin, A., 2020. Assessing batteries supply chain networks for low impact vehicles. Int. J. Energy Sect. Manag. 14, 148-171. https:// doi.org/10.1108/IJESM-11-2018-0004.
Reinhardt, R., Christodoulou, I., Gassó-Domingo, S., Amante García, B., 2019. Towards sustainable business models for electric vehicle battery second use: a critical review. J. Environ. Manag. 245, 432-446. https://doi.org/10.1016/j.jenvman.2019.05.095.

Roman, L., 2021. The 'Battery Passport' and the future of the auto industry - Everledger. URL. https://everledger.io/the-battery-passport-and-the-future-of-the-auto-indust ry/. (Accessed 1 December 2021).

Saberi, S., Kouhizadeh, M., Sarkis, J., Shen, L., 2019. Blockchain technology and its relationships to sustainable supply chain management. Int. J. Prod. Res. 57, 2117-2135. https://doi.org/10.1080/00207543.2018.1533261.

Saidani, M., Yannou, B., Leroy, Y., Cluzel, F., Kendall, A., 2019. A taxonomy of circular economy indicators. J. Clean. Prod. 207, 542-559. https://doi.org/10.1016/j. jclepro.2018.10.014.

Sarkis, J., Kouhizadeh, M., Zhu, Q.S., 2020. Digitalization and the greening of supply chains. Ind. Manag. Data Syst. 121, 65-68. https://doi.org/10.1108/IMDS-08-20200450 .

Saroha, M., Garg, D., Luthra, S., 2021. Identification and analysis of circular supply chain management practices for sustainability: a fuzzy-DEMATEL approach. Int. J. Prod. Perform. Manag. https://doi.org/10.1108/IJPPM-11-2020-0613 (in press).

Schöggl, J.P., Stumpf, L., Baumgartner, R.J., 2020. The narrative of sustainability and circular economy - a longitudinal review of two decades of research. Resour. Conserv. Recycl. 163, 105073 https://doi.org/10.1016/j.resconrec.2020.105073.

Sovacool, B.K., Kester, J., Noel, L., de Rubens, G.Z., 2019. Energy injustice and nordic electric mobility: inequality, elitism, and externalities in the electrification of vehicle-to-grid (V2G) transport. Ecol. Econ. 157, 205-217. https://doi.org/10.1016/ j.ecolecon.2018.11.013.

Stampatori, D., Raimondi, P.P., Noussan, M., 2020. Li-ion batteries: a review of a key technology for transport decarbonization. Energies 13, 2638. https://doi.org/ 10.3390/en13102638.

Talkhestani, B.A., Jazdi, N., Schloegl, W., Weyrich, M., 2018. Consistency check to synchronize the Digital Twin of manufacturing automation based on anchor points. Procedia CIRP 72, 159-164. https://doi.org/10.1016/j.procir.2018.03.166.

Tesla Inc., 2020. Tesla-Impact-Report 2019. URL. https://www.tesla.com/impact-re port/2019. (Accessed 1 December 2021).

Tsakalidis, A., Thiel, C., 2018. Electric Vehicles in Europe from 2010 to 2017: Is FullScale Commercialisation Beginning? an Overview of the Evolution of Electric Vehicles in Europe. EUR 29401EN, Publications Office of the European Union, Luxembourg. https://doi.org/10.2760/8053.

Ungurean, L., Cârstoiu, G., Micea, M.V., Groza, V., 2017. Battery state of health estimation: a structured review of models, methods and commercial devices. Int. J. Energy Res. 41, 151-181. https://doi.org/10.1002/er.3598.

Velázquez-Martínez, O., Valio, J., Santasalo-Aarnio, A., Reuter, M., Serna-Guerrero, R., 2019. A critical review of lithium-ion battery recycling processes from a circular economy perspective. Batteries 5. https://doi.org/10.3390/batteries5040068.

Walden, J., Steinbrecher, A., Marinkovic, M., 2021. Digital product passports as enabler of the circular economy. Chem. Ing. Tech. 93, 1717-1727. https://doi.org/10.1002/ cite. 202100121.

Wang, X.V., Wang, L., 2019. Digital twin-based WEEE recycling, recovery and remanufacturing in the background of Industry 4.0. Int. J. Prod. Res. 57, 3892-3902. https://doi.org/10.1080/00207543.2018.1497819.

World Economic Forum, 2019. A Vision For A Sustainable Battery Value Chain In 2030 Unlocking The Full Potential To Power Sustainable Development And Climate Change Mitigation. http://www3.weforum.org/docs/WEF_A_Vision_for_a_Sustain able_Battery_Value_Chain_in_2030_Report.pdf. (Accessed 1 December 2021).

Wrålsen, B., Prieto-Sandoval, V., Mejia-villa, A., Born, R.O., Hellström, M., Faessler, B., 2021. Circular business models for lithium-ion batteries - stakeholders , barriers , and drivers. J. Clean. Prod. 317, 128393 https://doi.org/10.1016/j. jclepro.2021.128393.

Xiong, R., Li, L., Tian, J., 2018. Towards a smarter battery management system: a critical review on battery state of health monitoring methods. J. Power Sources 405, 18-29. https://doi.org/10.1016/j.jpowsour.2018.10.019.

Zhang, A., Zhong, R.Y., Farooque, M., Kang, K., Venkatesh, V.G., 2020. Blockchain-based life cycle assessment: an implementation framework and system architecture. Resour. Conserv. Recycl. 152, 104512 https://doi.org/10.1016/j. resconrec.2019.104512. 